Portland State University

PDXScholar

$5-25-2019$

\title{
Architectural Stewardship: Exploring Interpretation Architecture through the Lens of the Visitor
}

Graham A. Oden

Portland State University

Follow this and additional works at: https://pdxscholar.library.pdx.edu/honorstheses

Part of the Architecture Commons

Let us know how access to this document benefits you.

\section{Recommended Citation}

Oden, Graham A., "Architectural Stewardship: Exploring Interpretation Architecture through the Lens of the Visitor" (2019). University Honors Theses. Paper 781.

https://doi.org/10.15760/honors.799

This Thesis is brought to you for free and open access. It has been accepted for inclusion in University Honors Theses by an authorized administrator of PDXScholar. Please contact us if we can make this document more accessible: pdxscholar@pdx.edu. 


\section{Architectural Stewardship:}

Exploring Interpretation Architecture through the Lens of the

by Graham Oden

An undergraduate honors thesis submitted in partial fulfillment of the requirements for the degree of Bachelor of Science in University Honors and Architecture

Thesis Adviser: Jeff Schnabel

Portland State University 2019 


\section{INTRODUCTION}

This undergraduate thesis investigates the experiential impact of interpretation architecture in the natural setting, specifically through the lens of its users. The purpose of doing so is first to see if my preconceived notions of this typology's influence hold true-l have created a list of criteria representing these notions and will evaluate them against an exploration of visitor experience and designs_-and second, to extend general and occupational awareness-encouraging architectural and spatial thinking in the visitor's mind when experiencing this, or any, typology and emboldening designers to utilize the voices of users of a space as a means of improving a design-for the typology as a whole as well as for the renovation of Great Sand Dunes National Park and Preserve's (GRSA's) Visitor Center.

The following sections of this document detail: a background of my motivation for conducting this study, the methods with which I carry it out, criteria developed from education and experience during my time with GRSA and Portland State University, a qualitative study of visitor insight and design expression through retrospective and proactive lenses, an evaluation of the aforementioned criteria using experiences and insights visitors express, noting possible methods for implementation into the design process, and finally proposing further areas for study in this subject.

With this thesis, I hope to further understanding of duties designers hold for the betterment of interpretation architecture through the eyes of its users. 


\section{BACKGROUND}

Based on my education so far, architecture is problem-solving through design to develop harmony between the environment, occupants, and purpose of space. Ideally, people arriving on any site for the first time begin to realize the architecture's function within the landscape and furthermore are able to conject relationships between the building, history of place and culture, and climate. Likewise, people who frequent the area may discover connections to the environment or root culture expressed in the building's design they had never noticed before.

My particular interest toward architecture in a natural setting and GRSA stems from a confluence of life interests. I was raised on the edge of a rural town an hour away from the park, visiting often on school and family trips. As my relationship grew with the park, I found myself participating in volunteer Wilderness stewardship backpacking trips offered by the park to high schoolers. After getting to know park staff and operations through this experience, I applied to become a student trainee park guide and worked toward becoming an Interpretation and Visitor Services Ranger. Also while in high school I began feeding a growing interest in architecture, taking classes alongside regular classwork. Working seasonally at the visitor center, while pursuing an architectural degree, bolstered my interest in architecture's role of creating the visitor experience in these natural settings. Even with this interest, however, I wasn't sure how their interaction would manifest in my life.

That is until my superior mentioned that our park would be receiving a renovation of its visitor center; I was elated at the possibilities. Through inspecting the schematic design put forth by the contracted firm and speaking with my Chief Ranger, I discovered that employee input was collected and used, along with the most recent 10 year old quantitative visitor use studies, but that visitors were not approached or included to be part of the design process or studies. This gap in engagement confused and drove me to address this lack of visitor input for the renovation and, ultimately, develop my thesis. 
This thesis considers a specific, currently underutilized design resource available within the efficacy of the Department of the Interior. It is also a means of developing a design process and list of values I can hold true to while continuing to explore the field of architecture. From this research, I plan to move forward by analyzing the current renovation plan of GRSA's Visitor Center and presenting my findings to the National Park Service and contracted company, provided there is still time for changes and adaptations.

\section{METHODS}

My thesis will address the question:

"Through the lens of the visitor, what recurring elements are considered successful in experiencing Interpretation Architecture in the natural setting?"

The criteria (listed in the following section) defining success in this context are based on personal experiences and beliefs that arose while working at Great Sand Dunes and from my educational pursuits. To see if and how this aligns with mass consensus of visitor experience, I will qualitatively examine both proactive input-visitor visions from a design workshop ranger program ${ }^{1}$-and retrospective input-online reviews ${ }^{2}$ of eight geographically and managerially diverse visitor centers encompassing the unique, natural environments of North America. Furthermore these centers are well received overall by public review. ${ }^{3}$ The proactive input provided by visitors of GRSA in conjunction with the broad patterns that arise from reviews of the other seven centers is used to carry out this evaluation of the initial criteria. My findings are intended to not only inform the current renovation of the Visitor Center at GRSA, but future projects of this typology as well.
${ }^{1}$ It is important to note that documentation of visitor input was carried out as part of the design workshop ranger program by the National Park Service. Though I was the one who initiated, got approval for, and then began conducting this program, it was as an employee, not a student. I refer to it in this thesis as I would any other external study, but with the benefit of personal insight.

${ }^{2}$ For the purposes of this study, Trip Advisor will be used because of its intuitive filter system and keyword presets, of which "visitor center" is already an option. This allows ease of exploring thoughts and impressions visitors had specifically toward this part of the experience.

${ }^{3}$ The intent behind this is not to neglect what is not working in the built environment, but to identify what is successful so that it may be sought after with more vigor and ease of access by designers, contractors, and organizations. 


\section{CRITERIA}

The following list of criteria will be used for analysis of Interpretation Architecture in a natural setting:

- It is a place at which anyone can learn about the resource ${ }^{4}$ in a memorable and experiential way so that they may develop perspective on contemporary life and an appreciation of what came before, what we have now, and what we can actively do to influence what we will have in the future.

- It is a place that houses visitor services in a way that does not dominate the landscape or influence or alter wildlife behavior; these services include but are not limited to visitor and resource protection and interpretation of the resource.

- It is a place that exemplifies extensive practical sustainable practices that reinforce preservation and conservation promoted by the entity within; it is a beacon of stewardship.

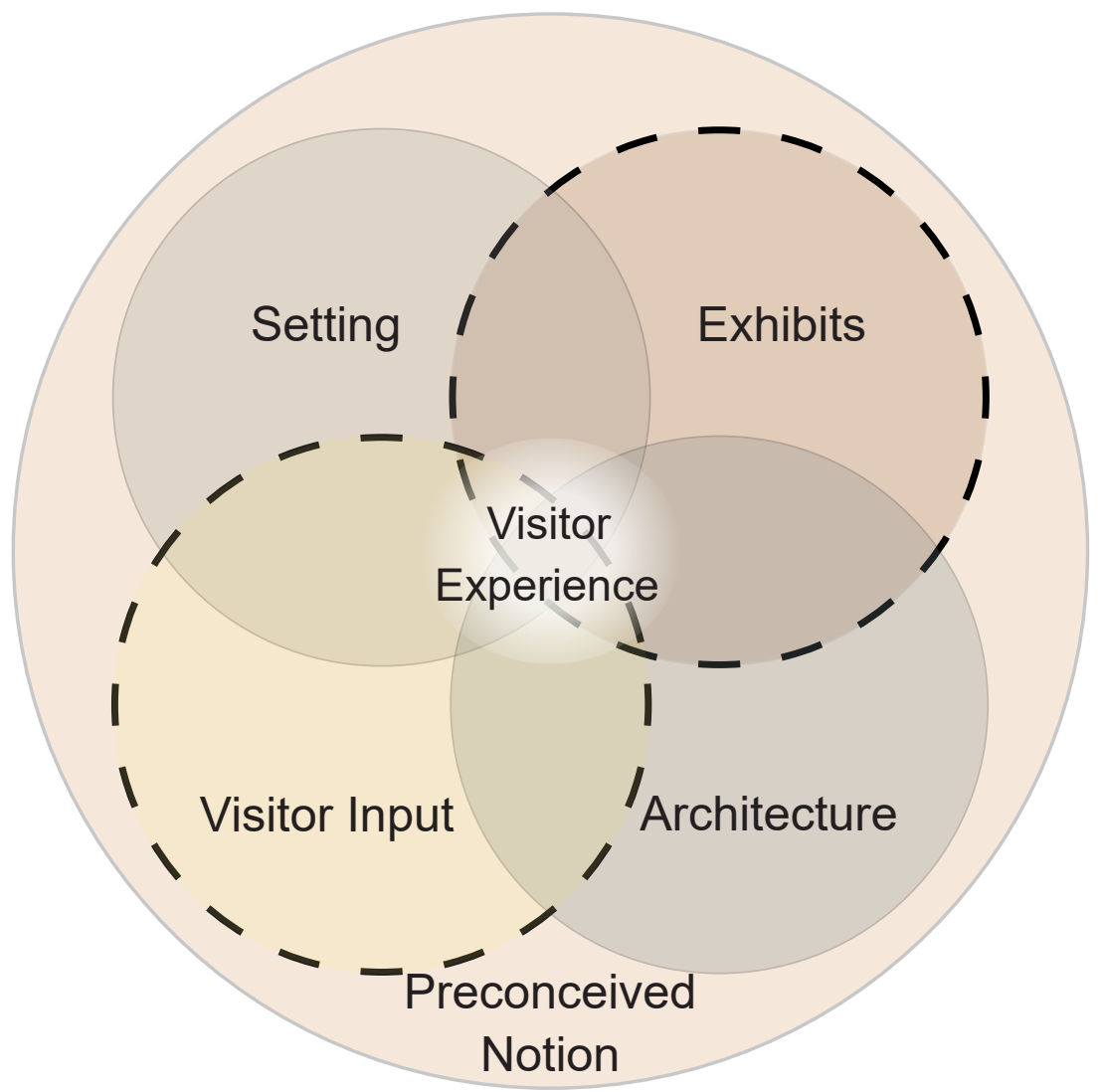

${ }^{4}$ "Resource" refers to geology of the area (how it formed and over what time period), previous and original cultures and how they navigated life amongst the wildlife and landscape, wildlife both past and presently living in the area; the comprehensive features, history, and qualities of an area.

This diagram visualizes my preconcieved notions of what fundamental and new elements (dashed border) comprise the visitor experience from the perspective of a student designer and park ranger. 


\section{Retrospective - Online Reviews}

\section{Hawaii}

Being one of the only two national parks in Hawaii, Haleakala is well reviewed on Trip Advisor (7,174 reviews at the time this is written) yet only a fraction, 788 , of reviews mention the visitor center (VC). Of those reviews, 649 are rated "excellent," 109 are "very good," 21 are "average," seven (7) are "poor," and two (2) are "terrible." A majority of visitor reviews contextualize the VC along the lines of "we saw the visitor center and it was closed (only open from sunrise to noon)...." But for those that were able to spend time at the center, most expressed appreciation for the views offered by the observation deck, the well-kept restrooms, and the loop trails originating from the VC. Other items of interest to visitors include the gift shop and the informative displays and exhibits detailing cultural tradition and heritage, native plant species, and geologic processes of the area.

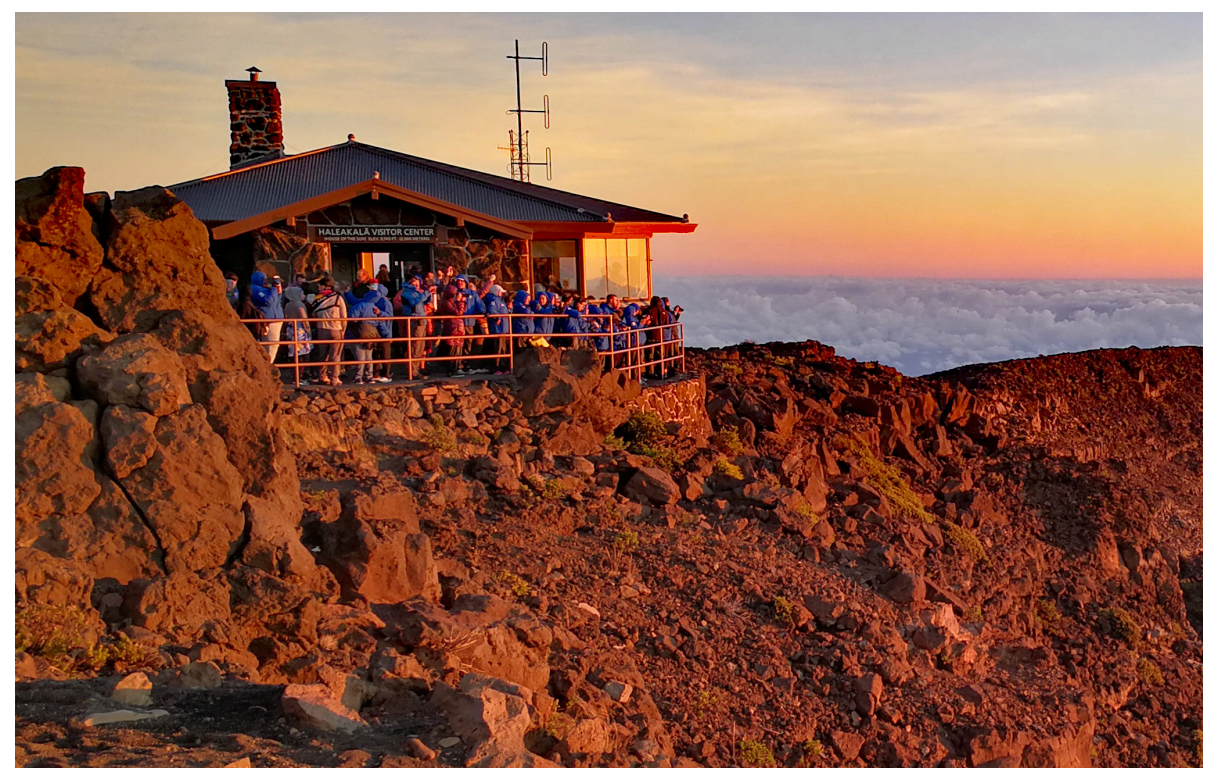

Photo Courtesy of Wikimedia Commons 


\section{Alaska}

Due to Alaska's massive amount of land, two different centers belonging to different organizations were explored. The first is the Alaskan Wildlife Conservation Center (AWCC), a 501 (c) 3 organization, and the second is the Kenai Fjords National Park, a unit of the National Park Service branch of the Department of the Interior.

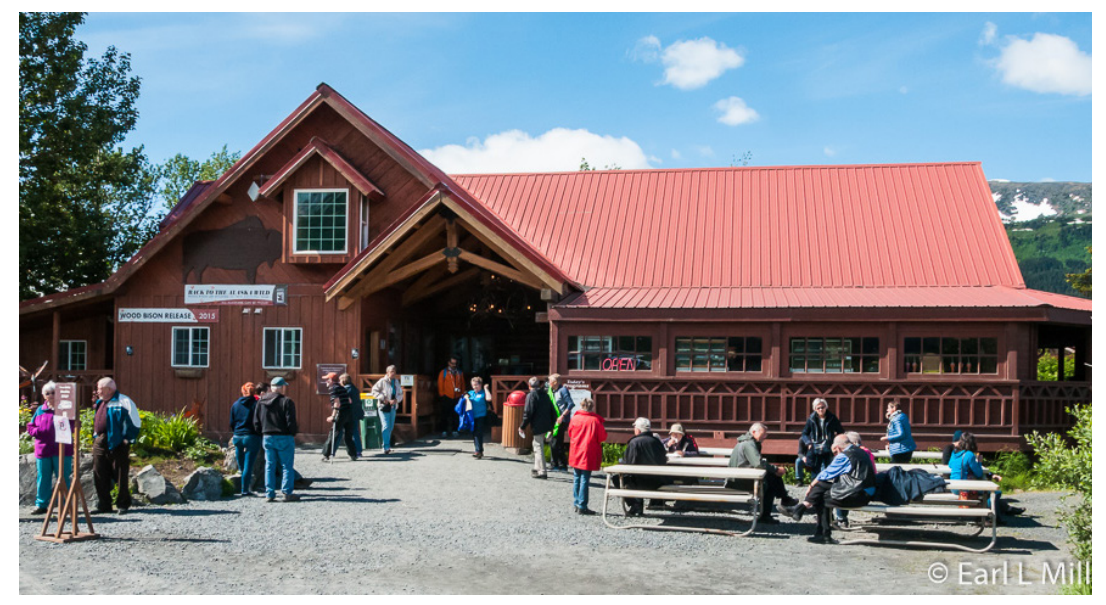

Photo Courtesy of Earl L Miller

For the AWCC, 66 of the 2,901 reviews mentioned the visitor center; 39 of the reviews were rated "excellent", 19 were "very good," six (6) were "average," and two (2) were "poor." The common point made by those who rated it excellent was the proximity to which they could experience wildlife. One specific example of this is the elevated bear walkway that allows visitors to get close to the bears while remaining safe. The opposite opinion was expressed, however, by those who rated it poorly. They noted that staff was missing an opportunity to teach caution and respect toward wildlife through the way they currently (at the time of that review) interact with the bears for visitors' entertainment. Other reviews expressed this concern further and claimed this place was more of a zoo than anything else. 


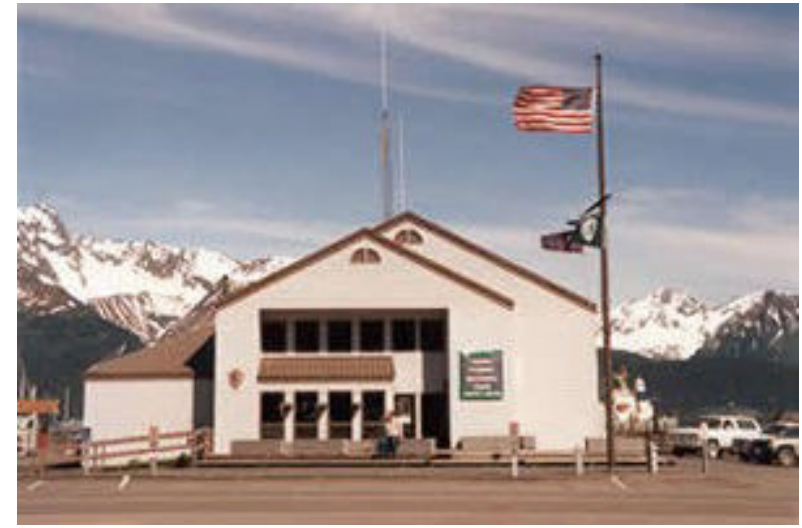

Photo Courtesy www.nps.gov/kefj

Kenai Fjords National Park (KEFJ) was chosen due to its high review count and low notoriety. KEFJ has 1,531 reviews on Trip Advisor and of them, 74 mention the visitor center. It is worth noting here that KEFJ technically has two visitor centers: Kenai Fjords National Park Visitor Center which is the center referred to in these reviews, and Exit Glacier Nature Center which will not be covered in this study. Of the filtered reviews, 62 are in the "excellent" category, nine (9) are "very good," and three (3) are "average." The main attraction of this park is whale watching, but it also has trails to glaciers and ice fields. Many reviews were from people who either spent a short time exploring the center before their boat tour or a long time because weather conditions canceled their adventures. Visitors appreciated the "good bathrooms," "excellent exhibits" via which you could "learn a lot in a short time," and the center's ability to "salvage a scrapped trip." 


\section{East Coast}

When exploring visitor reception of VCs on the East Coast, represented areas address the diverse latitudinal landscape it holds without straying too close to high population areas further north. This brought me from the Chincoteague National Wildlife Refuge (CNRW) in Virginia to the Everglades of Florida. Chincoteague is an island refuge on the Virginia coast reminiscent of Acadia NP and similar island sanctuaries.

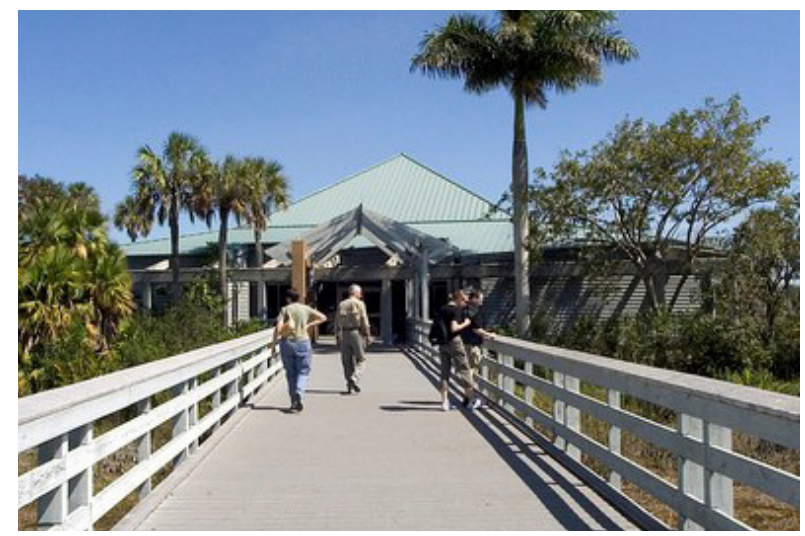

Photo Courtesy www.nps.gov/ever

The Everglades is home to the Earnest Coe, Flamingo, Shark Valley, and Gulf Coast visitor centers. Of the 1,317 reviews the Everglades have accrued on trip advisor, 213 directly mention "visitor center" in their text. The dispersal of ratings is favored in the "excellent" category with 140 reviews followed by 46 "very good" reviews, 20 "average," five (5) "poor," and two (2) "terrible." The "excellent" reviews commended the interactive info-graphics and that each visitor center was unique. The "average" review group was appreciative of the early opening hours, trails accessible from the center(s), and wheelchair access. The rest, "poor" and "terrible," were concerned about the condition of these centers post-natural-disaster and that they were not receiving the much needed maintenance and restoration they deserve. There was also an expressed disconnect between the feeling expected by visitors and the feeling experienced: some visitors expressed they were left wanting for an appreciation of the vast expanse of wilderness and more wheelchair access in the park and around the VCs. 


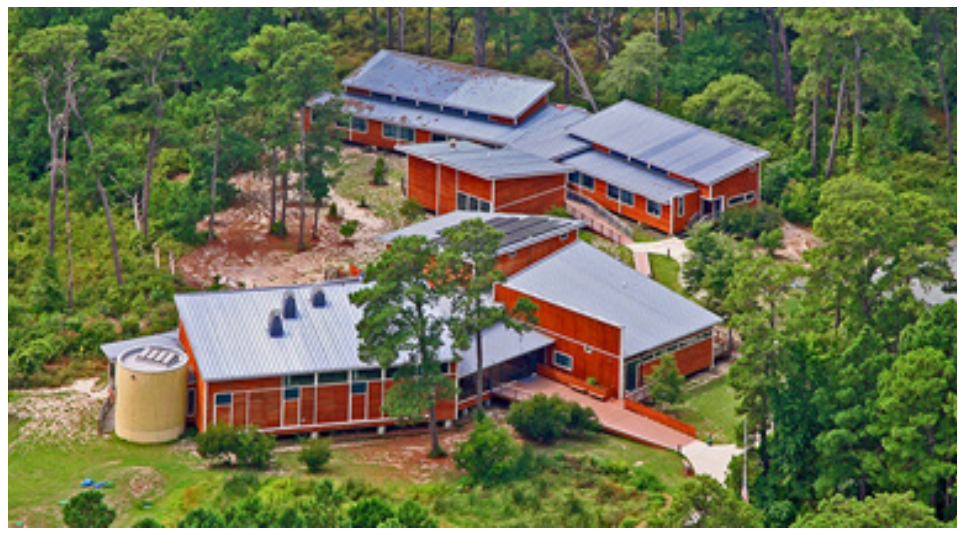

Photo Courtesy www.fws.gov/refuge/Chincoteague

Chincoteague National Wildlife Refuge has 2,742 reviews on Trip Advisor, 513 of which mention the term "visitor center." From these, 418 are "excellent," 77 are "very good," 16 are "average," and two (2) are "poor." Visitors expressed that Tom's Cove Visitor Center by the CNWR was engaging for children as well as adults, it provided contextual information in an effective manner, held a nice gift store, and (most importantly) provided visitors with clean washrooms and facilities. Concerns raised by visitors were primarily in regards to exterior conditions, such as "mosquitoes and rain," from which they celebrated the building's ability to provide shelter. 


\section{Central Midwest}

The Midwest is home to Appalachia and its surrounding natural resources like the Great Lakes. The first center l've looked at proxies the Great Lakes area: Porcupine Mountain Wilderness State Park (PMW) in Ontonagon, Michigan located on the southern coast of Lake Superior. The second is the ljams Nature Center (INC) in Knoxville, Tennessee within Appalachia.

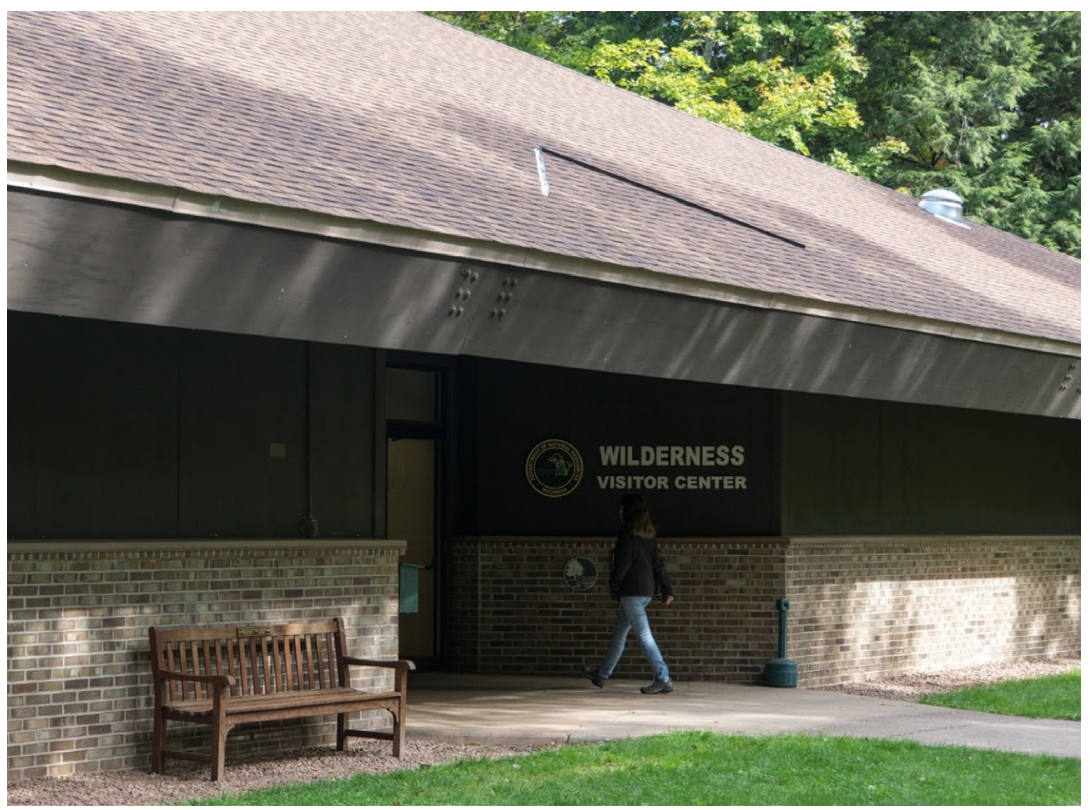

Photo Courtesy www.google.com/maps

PMW has a total of 517 visitor reviews submitted to Trip Advisor; of these, 58 mention its VC. Reviews expressed that overall the experience was "excellent" (46), while 11 reviews documented a "very good" rating for their time spent; only one (1) review was rated at "average." The main elements that visitors expressed appreciation for was the excellent quality of exhibits, maps, and general informational display. Exhibits included comprehensive collections of PMW fauna and "an excellent 20 minute movie [followed by a stop at the] gift shop." Furthermore, these exhibits were child friendly and engaging for the matured audience as well. This center was commended for providing initial orientation and information sought by visitors as well as easy access to spectacular scenery. 


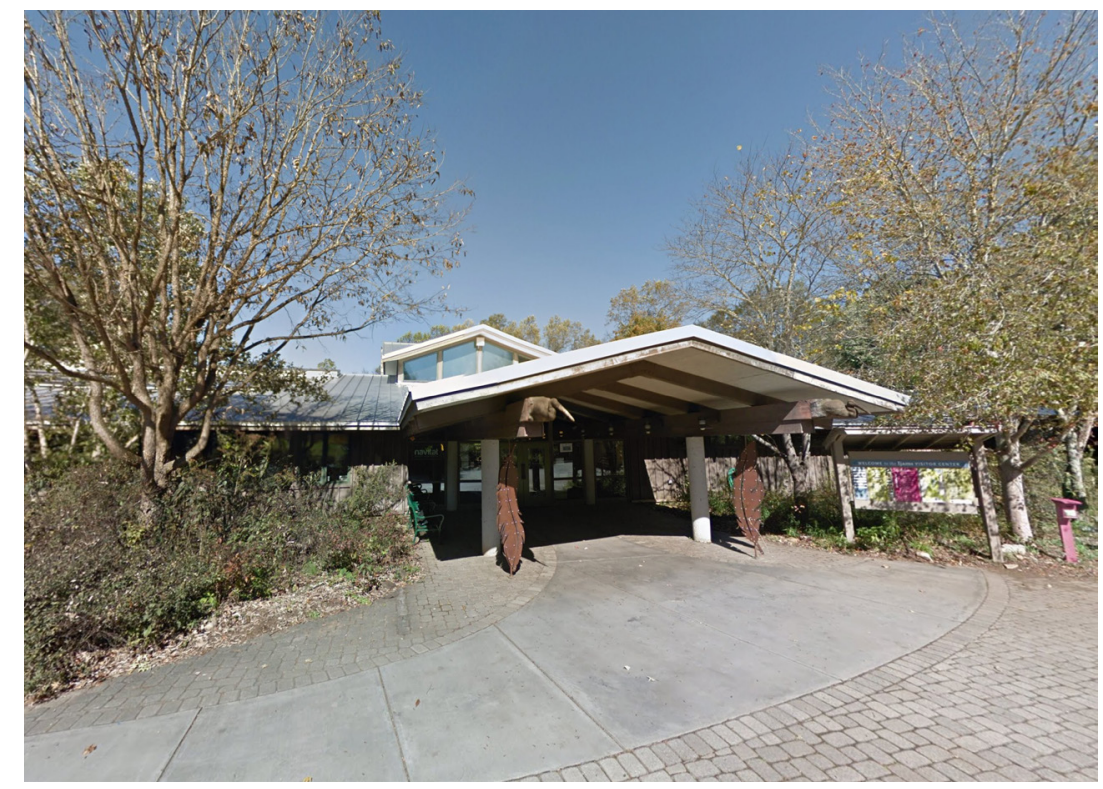

Photo Courtesy www.google.com/maps

INC has 731 reviews on Trip Advisor and of those, 76 mention the visitor center. The majority, 50, of these reviews, is in the "excellent" category, 23 are "very good," and one (1) remains for each of the "average," "poor," and "terrible" categories. From these reviews, visitors expressed that the visitor center has a communal function, hosting rotating exhibits and lectures as well as permanent displays. Most of the facility's resource management strategies are presented on a multifaceted level of graphic representation for a majority of audiences to understand their sustainable practices and implementations. There have been some reported issues with ADA access on a few trails claiming that designation, however, and some trails may benefit from further orientation sign-age. Overall, visitors expressed appreciation for the center being in near proximity to an urban area, but still located in a designated Wilderness area. Another common accolade was that they enjoyed the center's kid friendly, interactive exhibits. 


\section{West}

The West is defined by its deserts, prairies, and, of course, the Rocky Mountains. The final center of this study is located in Great Sand Dunes National Park \& Preserve (GRSA), a park that encompasses at least ten of the ecological zones found in Colorado and throughout the west.

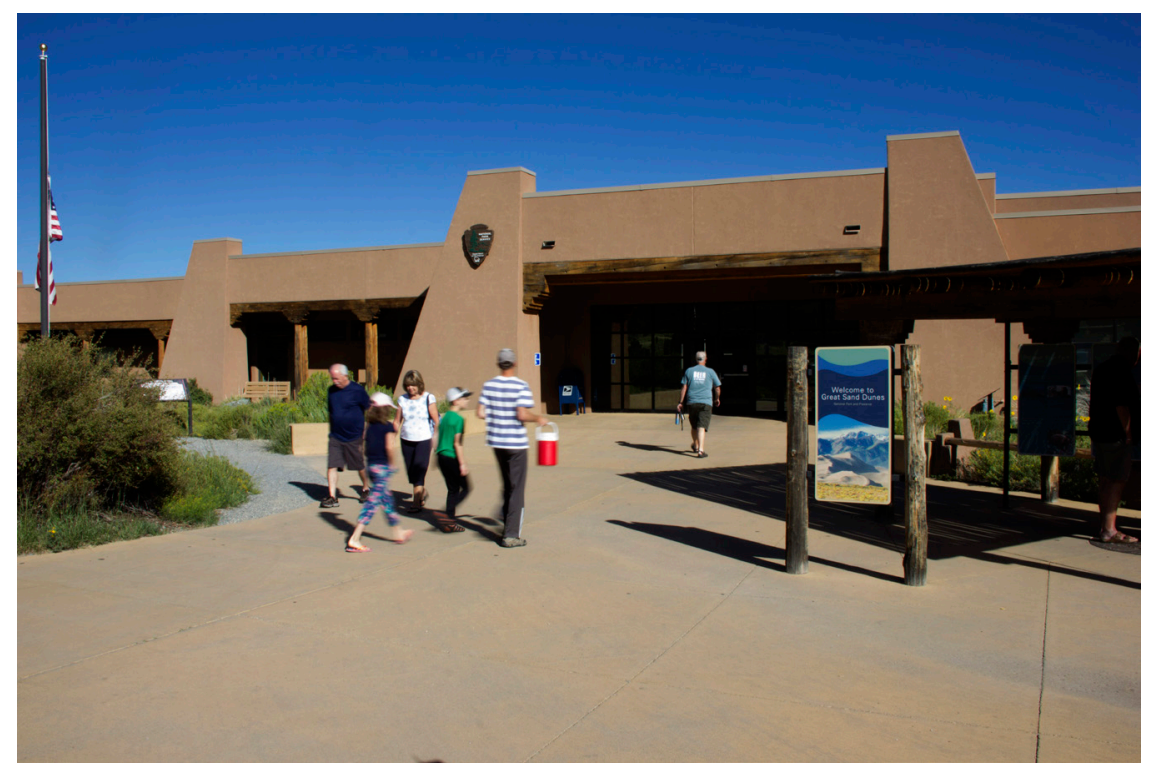

GRSA holds 731 reviews on trip advisor, 184 of which contain the phrase "visitor center." Of these, 144 are "excellent," 34 are "very good," five (5) are "average," and one (1) is "poor." Visitors primarily wrote of their experience learning about the park through the 20 minute film, exhibits, views, and access to trails from the visitor center. They appreciated explanations of geologic formations, history, and ecology through diverse means of display and representation. In addition to these educational elements, visitors expressed orientation and safety to be vital to their experience, knowing where to go when and what to expect made their experiences more valuable and enjoyable. Another aspect of the visitor center frequently mentioned was the gift shop, allowing visitors to pick up things like a memento to take home or some bug-repellent to deter pesky mosquitoes. Visitors also expressed the importance and appreciation of access to drinking water and restrooms. 


\section{Proactive - Design Workshop Results}

This section is an overview of the results of an open, free design workshop ranger program conducted at GRSA twice a week for two weeks. This program was piloted with the intent of having visitors design their ideal visitor center for the park ${ }^{5}$; their thoughts would then be communicated to the project manager and contracted company for consideration in the design process.

Participating visitors were diverse in nationality, age, gender, and familiarity with the park and wilderness. Though each visitor's design is unique and deserves its own attention, an effort of which is provided in the appendix, it is here that common and key design ideas will be highlighted:

Visitor's designs included forms of interactive exhibits and multimedia displays that gave them a deeper understanding of the park's geologic, cultural, and environmental history. One visitor spatially manifested this idea as a narrative occurring as one walks through the center. Other visitors had exhibits engaging their respective age group, including themed playgrounds, hostelries, and resting areas. Views were also a primary consideration; one visitor in particular had an entire second level dedicated to surveying the landscape. Another design uniformly allocated space for the park film, gift and necessities store, history and culture, and a new area dedicated to engaging children by means of assembling their own stuffed animal specific to park wildlife through an educational process akin to that of build-a-bear workshop. There were even some visitors that expressed having minor changes in lieu of a renovation altogether.
${ }^{5}$ This program was primarily inspired by the work of James Rojas \& Catalytic Communities. ("'City as Play' CommunityCentered Design Workshop." http://catcomm.org/city-as-play/) A rough draft of the program outline is also present in the appendix 


\section{ANALYSIS}

From qualitative analysis of retrospective visitor input, there are recurring experiences that arise and share connections with one another. I have categorized these experiences as: Education, Orientation, Recreation, Connection, and Recuperation. It is important to reaffirm that these are not intended to be an end-all-be-all when considering the experience of the visitor, but rather to assemble a collage of their voice at this point in time.

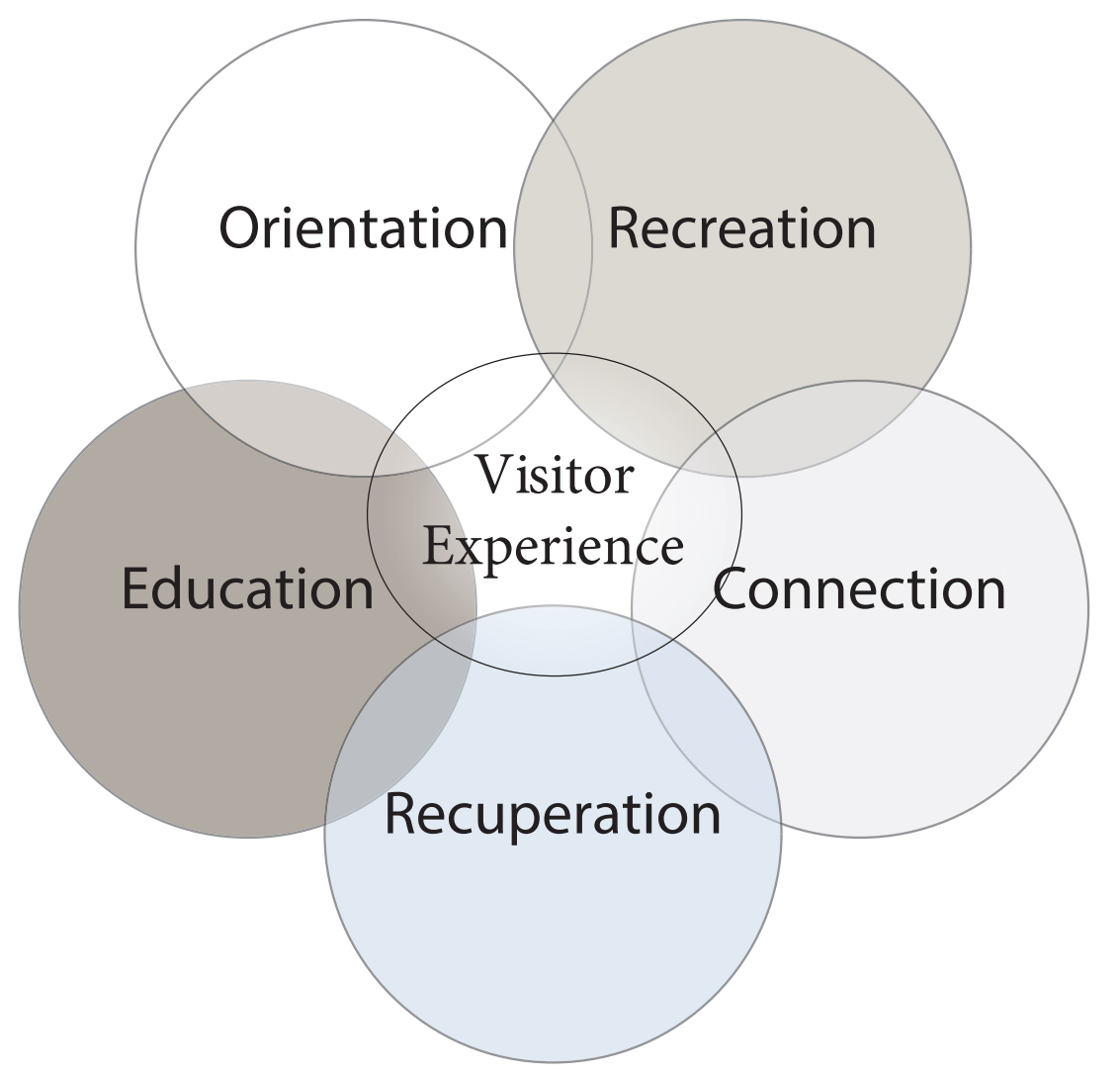

The first category of experience is Education; information and explanations feed visitor curiosity and give a comprehensive understanding of the specific area they are visiting. Visitors appreciate multifaceted, diverse, and engaging presentation of geology, ecology, and history, appropriate for all age groups.

The next is Orientation; similar to education, how visitors spend their time is important to them. Whether they have planned ahead or not, knowing current conditions of trails, weather concerns, alternative ways to spend their time, or what clothing and shoes are best to wear for an adventure yet to be had is crucial to the enjoyment of their time in the park. 
The adventure yet to be had entails Recreation; visitors enjoyed and designed spaces and places for involved and interactive programs, access to loop trails from the visitor center, and information, gear, and permits for extensive experiences in the heart of Wilderness.

Following Recreation, Connection encompasses a center's proximity to, or lack thereof for preservation purposes, its namesake attraction; this is also characterized by incorporating the ties a center has with its landscape, cultural history, and ecology into the visitor experience. Visitors liked being able to walk along trails from the visitor center or nearby parking lots, and centers designed featured local materials and forms that harkened to the landscape. They also wished to have expansive and strategically framed views of the surrounding landscape to get a sense of context.

Views are also enjoyed leisurely and lead to the next category of visitor experience: Recuperation. This category includes everything from basic needs like restrooms and drinking water, to a gift shop and resting area. In addition to it being a frequently asked question when working at the park, the location of restrooms was present and well-marked on most visitor designs and mentioned in a majority of the reviews. Another aspect of recuperation is shelter; visitors were grateful to have a place to go when external environmental conditions were undesirable or even dangerous. 


\section{CRITERIAL COMPARISON}

The notions I held (restated to the right) appear to remain mostly unexpressed, and for those that were, it was done so in different capacities than expected or previously thought. Likewise, the reviews and designs carried with them a functional and experiential language, expressed at a level of common access rather than veiled by architectural or academic jargon.

For example, the first criteria can truly fall under any and all identified categories of visitor experience. However, the elements that created these experiences (exhibits, interpretive films, and interactive displays) were not described architecturally, as having an architectural nature, or even indicated to hold any spatial qualities. Notably the exception to this is of the spaces developed in the design workshop, but even those were not described in great detail. ${ }^{6}$ The second and third criteria are missing entirely from visitor expression, but can be incorporated into the experiential categories of Recreation, Connection, and Education. There were a few designs that began to address the locality and sustainability through the use of local goods, sustainable practices, and regional materials.

It is valuable, then, to think of what reasons there are for this misalignment, a gap in language similar to that of the gap left by the contracted company. It is entirely possible that any visitor holds an inherent understanding of spatial qualities and experiences within a place just as architects are trained to have, the only difference being that visitors may have an easier time communicating it colloquially. Another possibility, though less likely, is that visitors pay little attention to the architecture in front of them, suggesting that interpretation architecture has a long way to go before it can consider itself successful. Realistically, however, I believe that the truth lies somewhere in the middle. Visitors experience exhibits and films, needs and mementos, parking lots and views, all of which architecture has the opportunity to play an active role in. Architecture houses these elements and can choose to do so overtly, covertly, or somewhere in between. These places require a balance of externally harkening to the land while telling its story within.
- It is a place at which anyone can learn about the resource ${ }^{4}$ in a memorable and experiential way so that they may develop perspective on contemporary life and an appreciation of what came before, what we have now, and what we can actively do to influence what we will have in the future.

- It is a place that houses visitor services in a way that does not dominate the landscape or influence or alter wildlife behavior; these services include but are not limited to visitor and resource protection and interpretation of the resource.

- It is a place that exemplifies extensive practical sustainable practices that reinforce preservation and conservation promoted by the entity within; it is a beacon of stewardship.

${ }^{6}$ It is also worth noting that visitor designs were communicated to and documented by the ranger immediately following the program, but that design descriptions, as honest of an attempt to represent visitor designs as they were, are written from immediate recall of those conversations rather than by direct transcript from the visitor (with the exception of written comments visible in those documents). 


\section{CONCLUSION}

This undergraduate thesis sought to investigate the experiential impact of interpretation architecture in the natural setting, specifically through the lens of the visitor. The need for this study arose from the fact that visitors were not approached or included to be part of the design process or studies in GRSA's Visitor Center renovation beyond the ten year old quantitative studies provided by the park. This gap in user engagement drove me to address the oversight by gathering visitor input for the renovation and ultimately develop this thesis. Both proactive (input gathered for the upcoming GRSA renovation) and retrospective (input in the form of trip advisor reviews) visitor input was qualitatively examined. From this, five categories of visitor experience emerged: Education, Orientation, Recreation, Connection, and Recuperation. After this examination, preconceived notions of this architectural typology, based on personal experience and education, were evaluated. This evaluation brought up questions for further study and consideration in interpretation architecture design.

My thesis set out to answer the question:

"Through the lens of the visitor, what recurring elements are considered successful in experiencing Interpretation Architecture in the natural setting?"

But from what I found, the question more appropriate to consider is:

"Through the lens of the visitor, what basic elements contribute to the visitor experience, and what aspects of each element are considered successful? For further exploration, how might these then be expressed architecturally?"

For visitors, I invite you to look more closely at the buildings around you, they may be trying to tell you something; and for designers, I challenge you to seek input and suggestions from all who may become subject to your designs, they undoubtedly have valuable insight and perspective that can only benefit the design and thereby, the final product. 


\section{BIBLIOGRAPHY}

"'City as Play' Community-Centered Design Workshop."

Catalytic Communities | CatComm (blog). Accessed May 24, 2019. http://catcomm.org/city-as-play/.

Cook, Kerry Lee. "An Interpretive Exhibit Design, Using Thematic and Graphic Design Concepts." M.A.P., Alaska Pacific University, 2016. https://search.proquest.com/ docview/1783114214/abstract/E697C61779014513PQ/1.

United States, National Park Service. Architectural Character Guidelines: Sequoia \& Kings Canyon National Parks. USDeptof the Interior, National Park Service, 1989. http://hdl.handle. net/2027/mdp.39015014988607.

United States. National Park Service. Design Process:

National Park Service. Denver, Colo.?]: USDepartment of the Interior, National Park Service, 1989.

Gross, Michael P., and Ron P. Zimmerman. Interpretive Centers: The History, Design, and Development of Nature and Visitor Centers. Stevens Point, Wisconsin, U.S.A.: Schmeeckle Reserve, 2002. 


\section{APPENDIX}

Graham Program

Title: It Takes a Visitor to Raise a Visitor Center (50min - $1 \mathrm{hr}$ )

Description: Come one, come all (Including Children!) to this design workshop to discover how YOU, our visitors, would design a space to deepen your connection to the park. This Ranger led, creative, collaborative exercise will encourage you to make your own Great Sand Dunes Visitor Center! The workshop will give us your voice in the upcoming renovation of our Visitor Center!

Tentative Schedule:

- First 5 min:

- Introduce design exercise in which visitors can make their ideal visitor center for GRSA

- Visitor Center is meant to be a physical manifestation of the resources that assist the visitor in exploring and discovering the importance of this place.

- Prompt questions:

- How do you enter the space? What is the first thing you encounter in your center and why?

- How can the space also serve those who aren't as mobile?

- How do you want to move through the story of our park? Chronologically? Following a particular historic figure? Or perhaps as a sand grain?

- Next 20 min:

- Visitors will organize color coded objects of varying size and shape to create their ideal visitor center while keeping in mind the prompt questions

- Kids are encouraged to have their own layouts separate from that of their parents so that designs represent a range of age groups.

$\circ$ Objects won't be glued down yet

- Next 5-10 min:

○ Visitors will share their general layout and what makes their Visitor Center Unique and specific to this park.

- Next 10-15 min:

- Visitors will be given the current Floor Plan of GRSA's VC and be told to do their best to fit their carte blanch design to the existing building.

- What aspects of their design are they prioritizing and why?

- Where will you put interp offices and where will the store go?

- How should the exhibits be set up to best tell the story of GRSA?

$\circ$ Once they have the layout they are happy with, they can glue pieces in.

- Next 5-10 min:

- Visitors will look at each other's designs and share their ideas with the group

- We will write down ones that everyone agrees with.

- Next 5-10 min:

- The current scheme proposed by EDX will be displayed and visitors will bring up similarities and differences between it and their own designs 
This visitor's design was all about having a circular space in which the visitor could enjoy a panoramic view of the entire park. The space would be divided into sections so that as one walks around it, they still have a view outside.

Implementing this idea into the current $\mathrm{VC}$, this visitor decided there should be ADA ramps leading to a second floor to serve the panoramic purposes of the first design.

The first level is open with rounded northwest and southeast walls to echo the vantage point above. It holds designated areas for the shop, interactive learning spaces, ranger desk, flora and fauna, and geologic system. All were surrounding a mock dune field for kids to play in and those less mobile to be able to experience.
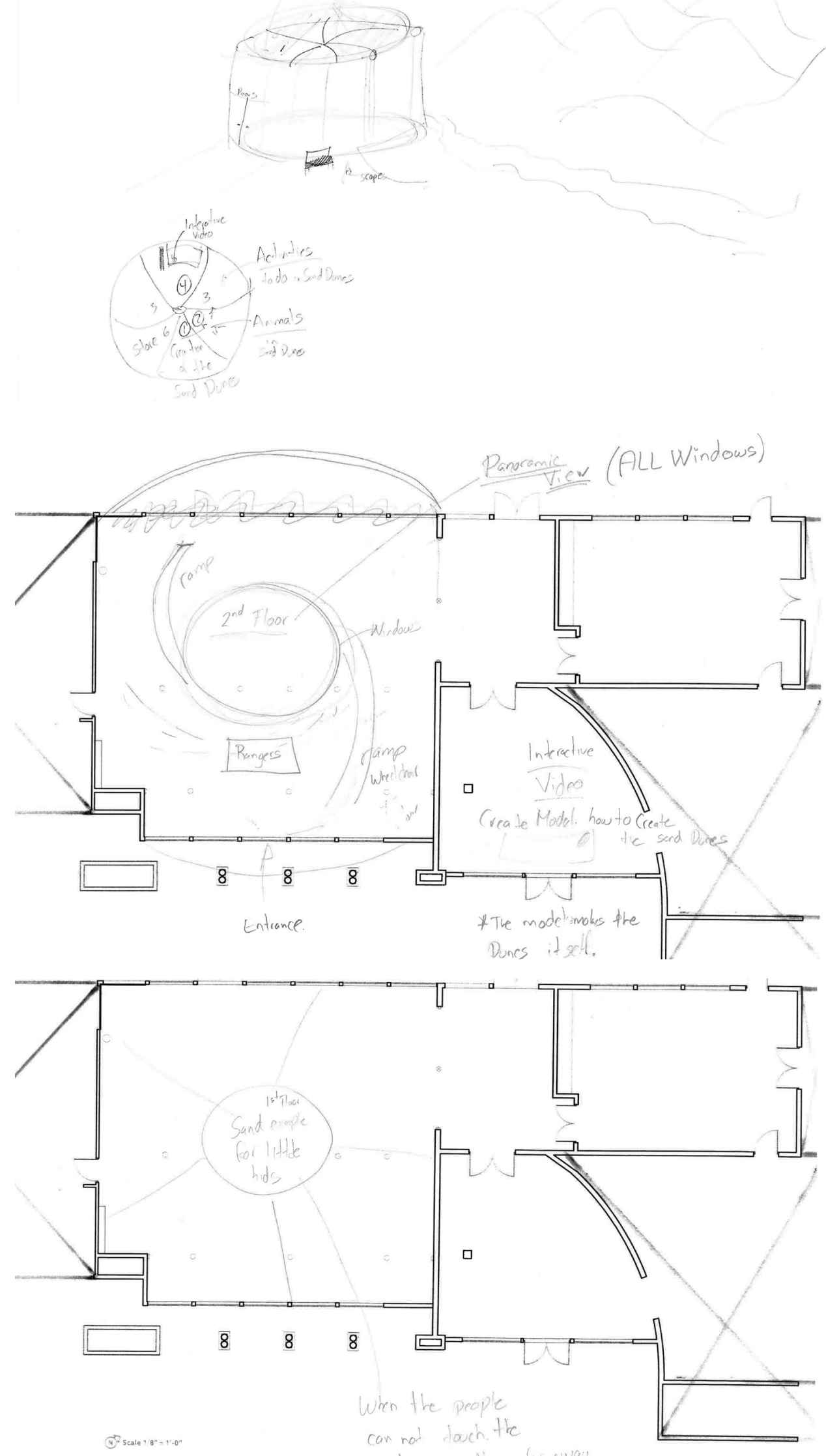


\section{Visitors 2 and 3 - Design}

This was a collaborative design between two visitors.

Their design quarters the visitor center into main areas with the information desk in the center. The first area, bottom left, is a children's section where they can learn about and make their own wild animals found in the park, much like "build-a-bear" workshop. It includes interactive learning spaces where they can model their own dune systems. The area to the right is another interactive learning space for an older audience. It details cultural history of the park, flora and fauna, and the dune field's unique geological and hydrological systems. The park store, upper right, features local products. The final area in the upper left is a theater space comparable to an IMAX.

Implementing this idea into the current VC, these visitors decided the upper age interactive section should be the first space encountered, with an unimpeded view to the dune field from the entrance. The children's area is located further inside to the right. The park store, complete with a local snack and beverage bar is across from the children's area. The film is then adjacent to the store with its outer walls detailing activities and wildlife in the park. Inside, the movie room is now a walk-along adventure through the park leading to the film.
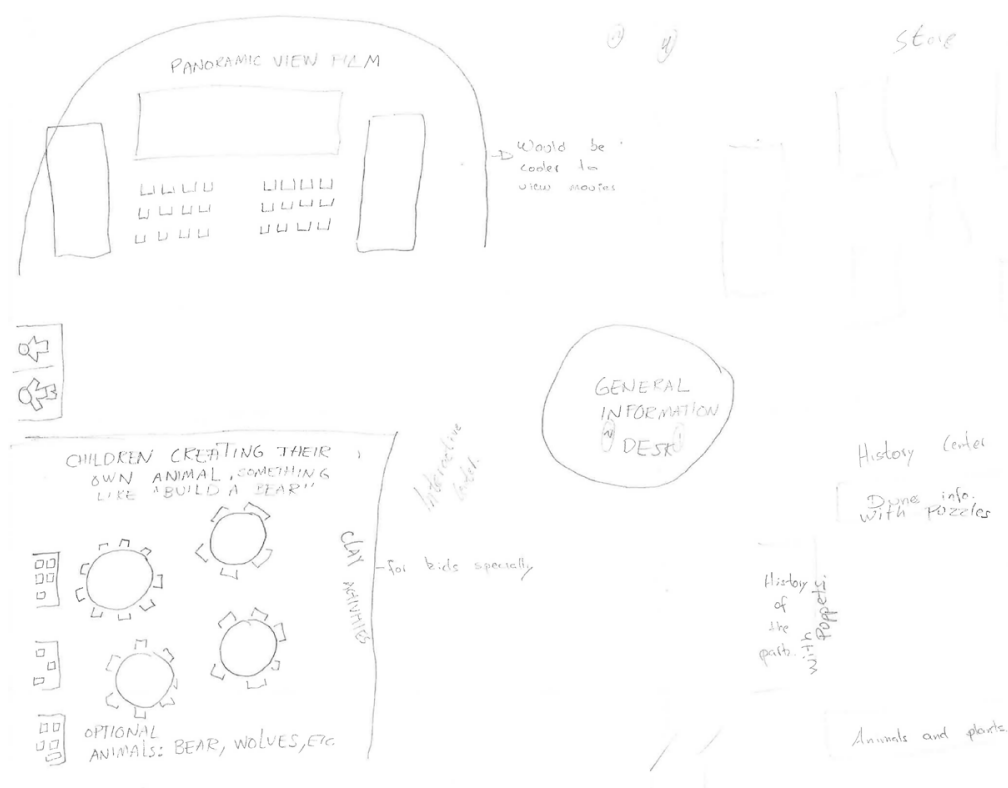

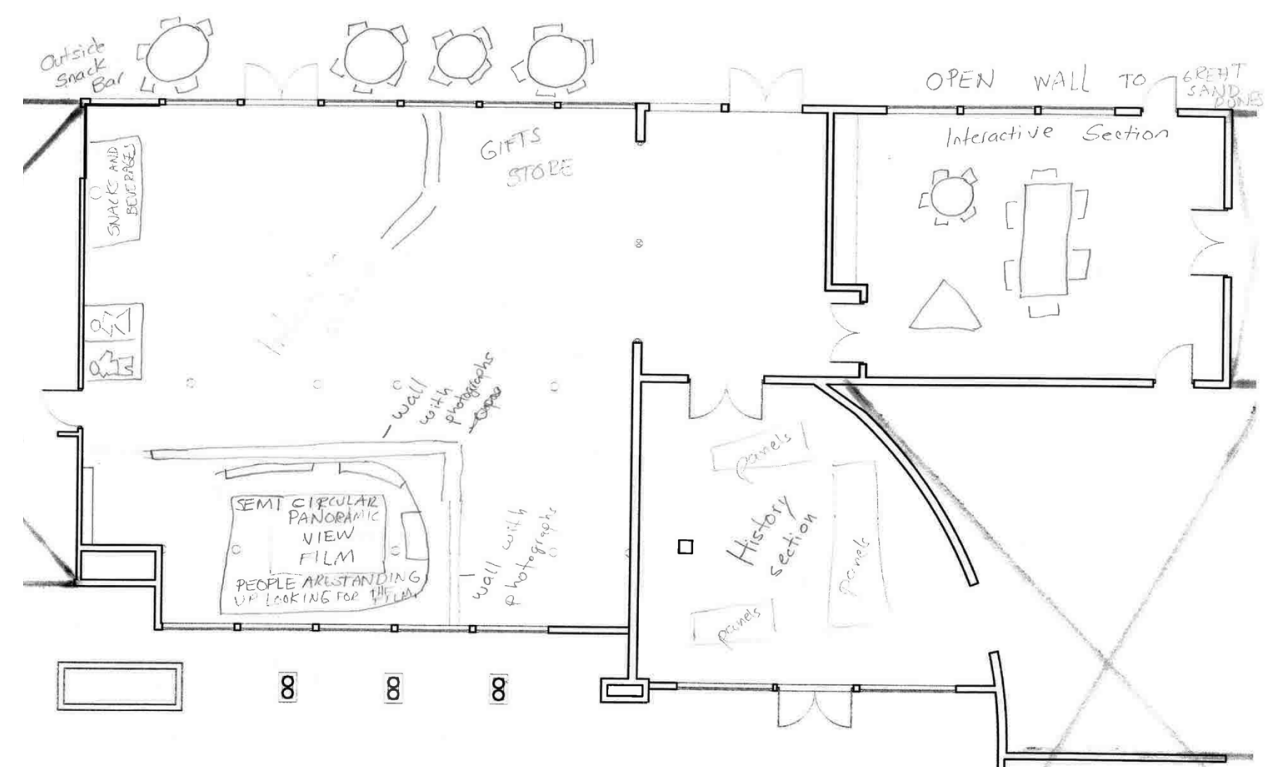


Visitor 4 - Written Comment

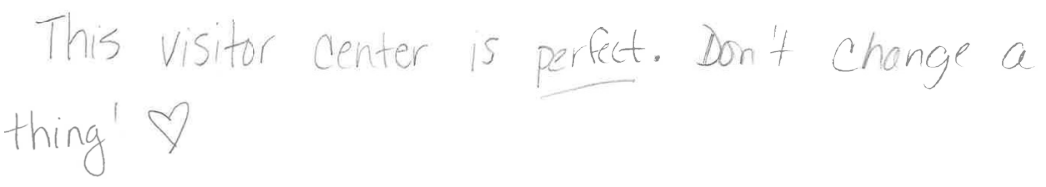

Visitor 5 - Written Comment

"Idea:

The movie right outside the door to the theater on 'How were the Dunes formed?' is great. [However,] it's tough to follow because one has to read the words too quickly at the same time that one has to see the picture/diagrams. If the words were spoken, it would Ilea: really help. Even better, it could be added to the 20 minute movie." 


\section{Visitor 6 - Design}

This visitor's design was all about having a coherent walk-through visitor center with trails sprouting from it to different places in the park. Entering, the visitor is greeted by a welcome sign detailing the function of this center and introducing them to the park. The visitor walks clockwise through the space, first along the water and wind systems that keep the dune field in place, followed by the flora and fauna that inhabit the park, they are then met with the park in different seasons explaining how life changes for its aforementioned inhabitants. Windows framing the dune field then meet the visitor and give them their first glance of the park with this newfound knowledge. They then come to an interactive exhibit detailing
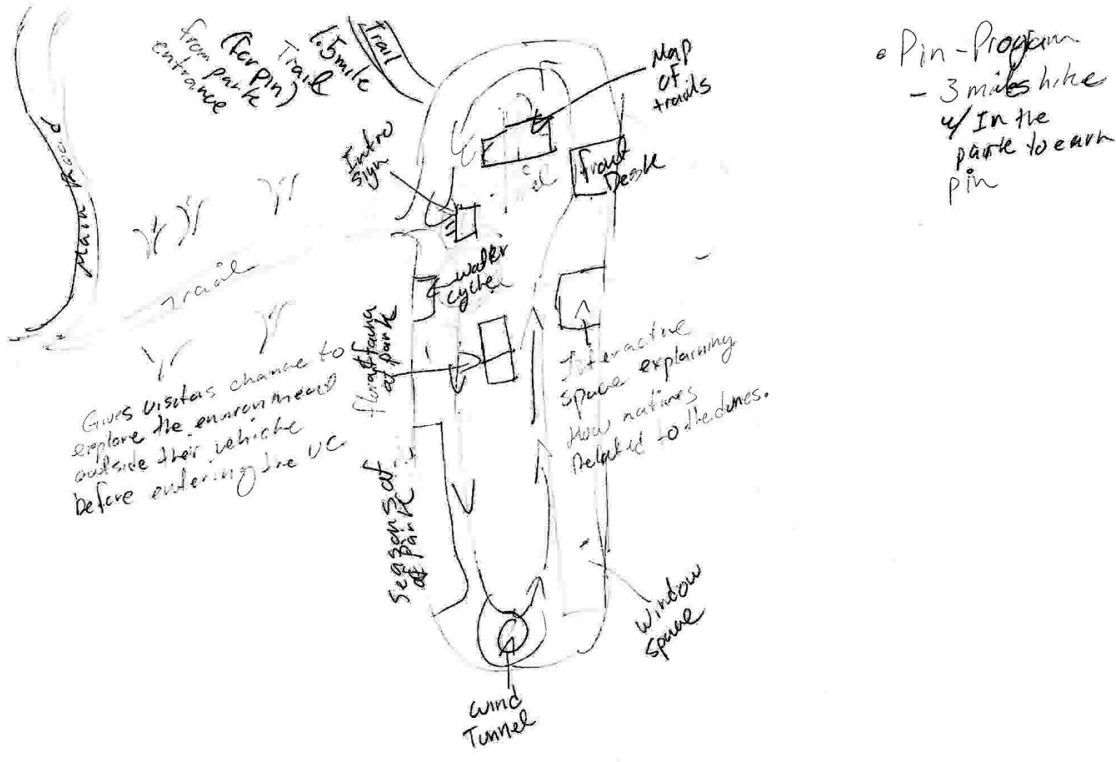

how past peoples utilized the parks environment to survive. After learning about the park this way, visitors can then talk to rangers for further knowledge and orientation in the park. Trail information and maps are located adjacent to the front desk next to a door leading to trail heads.
Implementing this idea into the current VC, this visitor opened the floor space entirely, with the exception of the entry keeping its curved ecological zone diorama and holding a night experience space behind the intro sign immediately adjacent to the entry. The rest of his design remains the same with the inclusion of a park store in the northwest corner and a covered patio for ranger programs and activities accessed through the south corner.

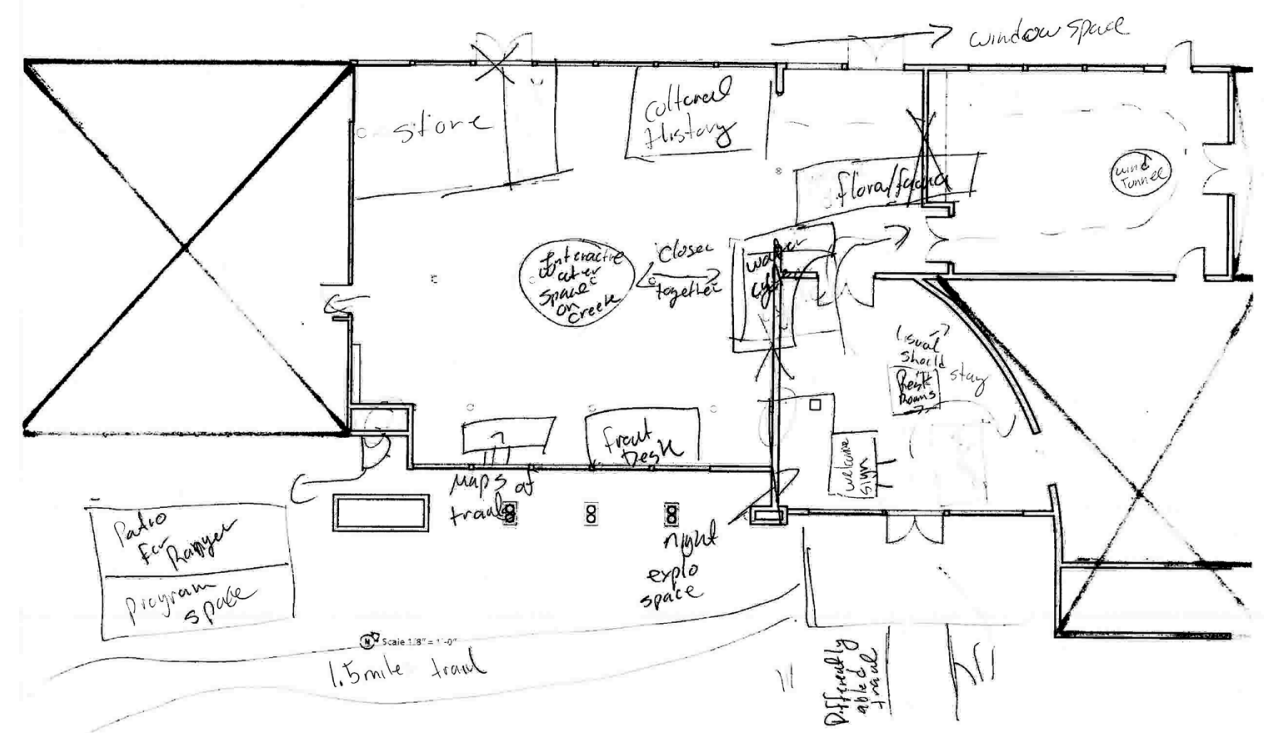




\section{Visitor 7 - Design}

\section{Visitors 7 and 8 were} co-traveling college students.

This visitor's design featured several satirical design ideas such as "an elevator that goes all the way to the bottom of the sand [deposit], up to depths of $300 f t$ " and "[getting] a resident bear." I believe this was done, in addition to having fun, with the intent to juxtapose their absurdness with the genuine and well thought out ideas as follows:

"Have more cool museum exhibits where you can learn about the dunes [and animals that live in them], like being able to act as a kangaroo rat."

"Keep the visitor [center] as is ... and spend funding on an observatory to really drive home the whole starry sky thing."

When implementing these ideas into the current $\mathrm{VC}$, this visitor decided to go primarily with their "keep the visitor [center] as is" plan, with the addition of an observatory located between the parking lot and the visitor center. He included that the current movie room should be changed into an interactive exhibit space.

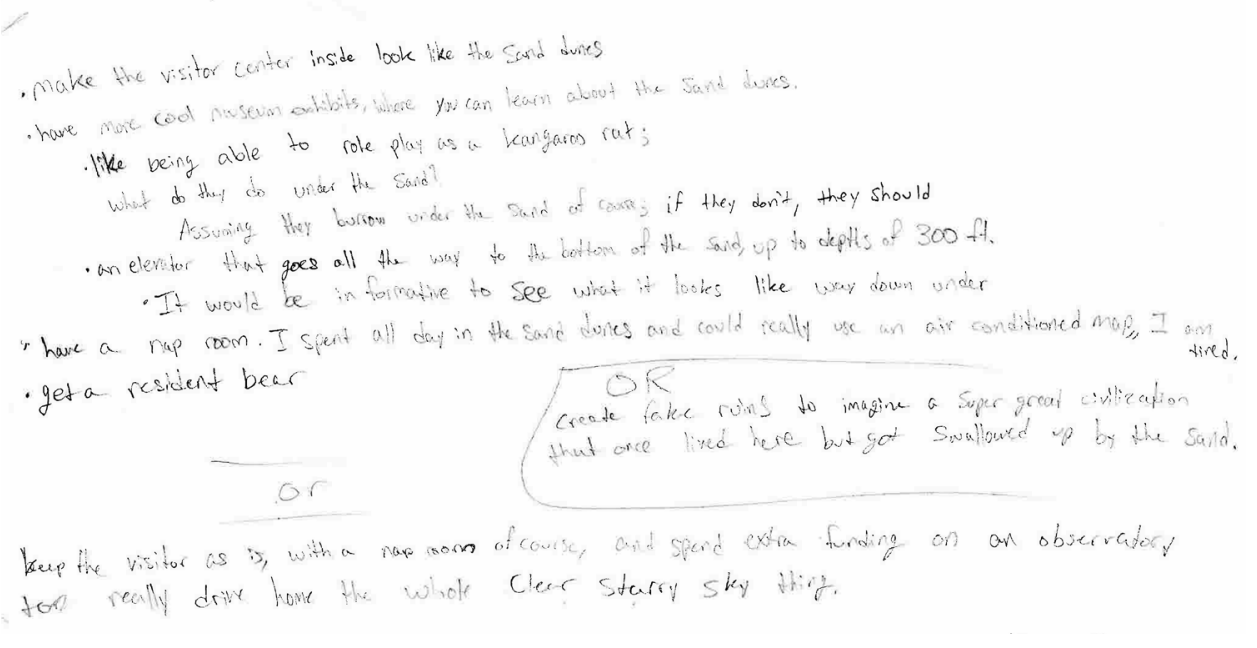

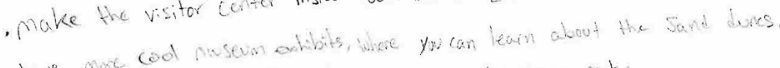

We being able to role play as a kangaros rut

do the co un ar the coses if they don't, they should

It would be in tormane to see what it looks like way down under

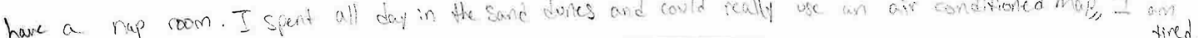

- get a resident bear

crente fake bed here but got swallowed up by the said.

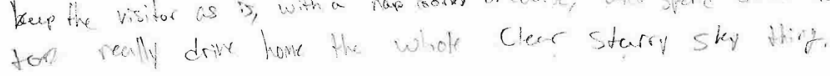




\section{Visitor 8 - Design}

This visitor's design was definitely on the satirical/ self-amusement side with not much applicable input, unfortunately. Until, that is, he was given a floor plan to put his ideas into.

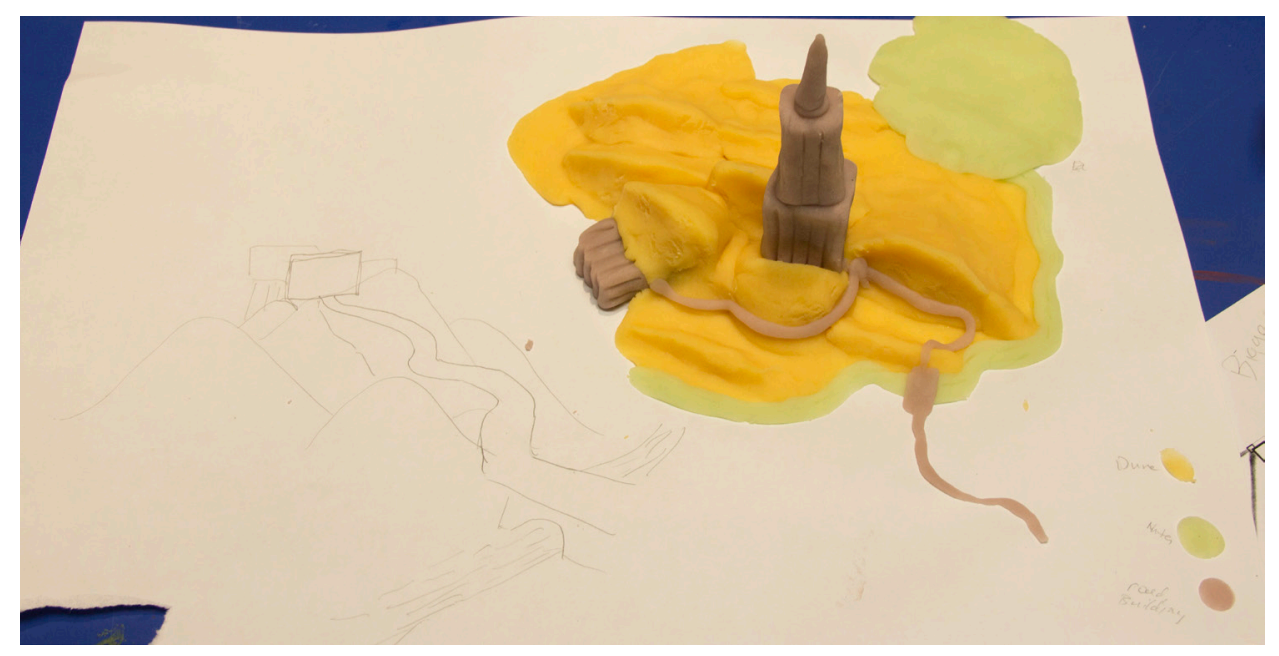

He decided there should be a larger patio space in order to enlarge and update the movie room, complete with a new film produced with state of the art effects and well-known actors/actresses, "like Neil deGrasse Tyson's 'Cosmos." $\mathrm{He}$ also included a basement bar, representative of having a space that connects with young adults too.

Despite the overt satire in his design, he and his friend were genuinely curious about what

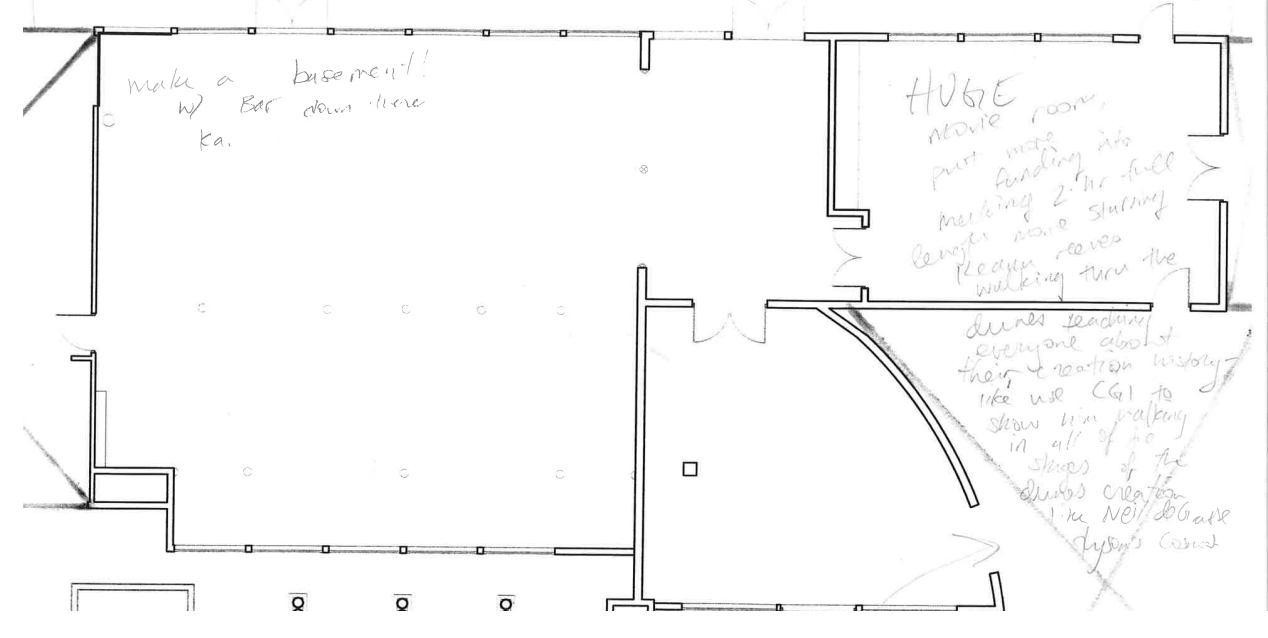
the dune field environment was like from a cross-sectioned view. 
Visitors 9 and 10 are siblings.

This young visitor was mostly concerned with having a fun visitor center. Having areas for kids to really connect with and learn to appreciate parks as they go through school. Outside, there is a mock dunes environment playground complete with the appropriate flora like scurf pea, rabbit brush, and prickly

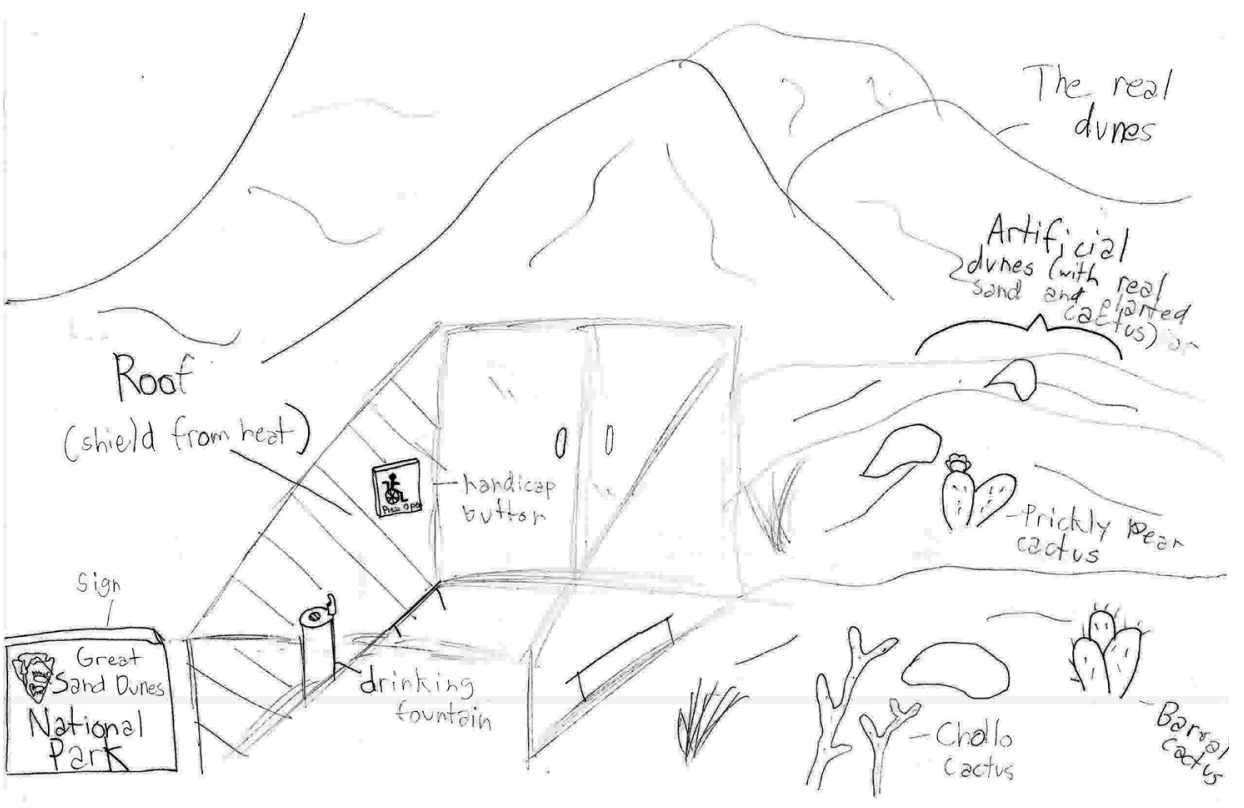
pear. He dedicated a whole space to the Junior Ranger program including an area for each aspect of the park, from sculpting sand dunes, to learning about wildlife in the park.

During the second part of the program, he really got into the logistics of our VC having a sand sledding outfitter. Overall, his layout of the visitor center isn't much different from how it exists currently. The only modifications to note are that the majority of interpretive and interactive exhibits are found in the lobby and the outer entrance of the building, encountered immediately by visitors.
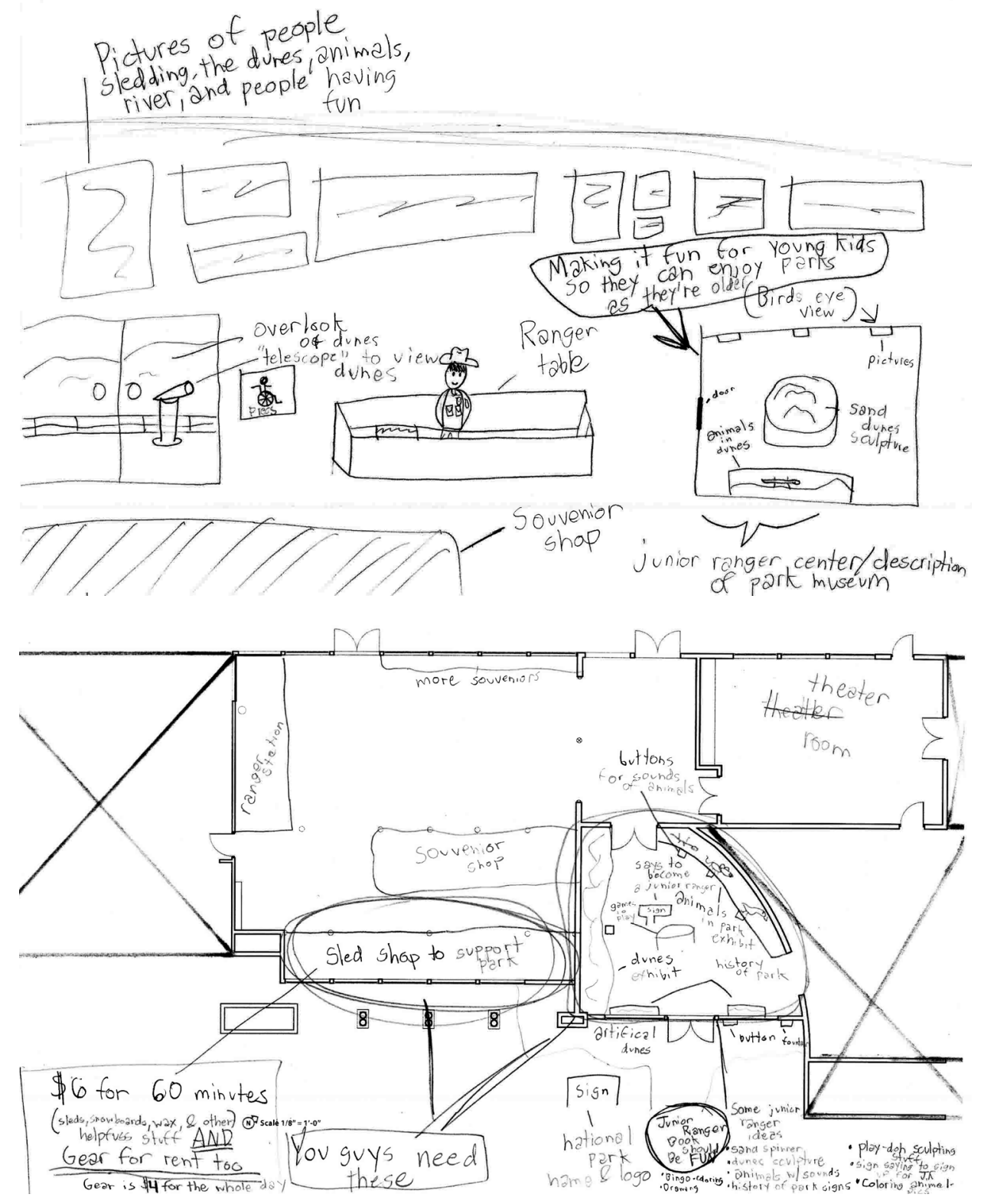


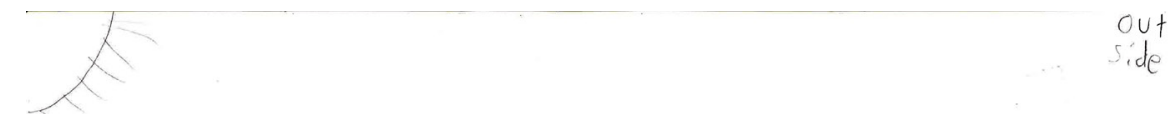

Primarily, this young visitor's design focused on having a time efficient parking lot with areas closest to the entry having a time limit on its use. It was also important to her that the restrooms were well marked and conveniently located.

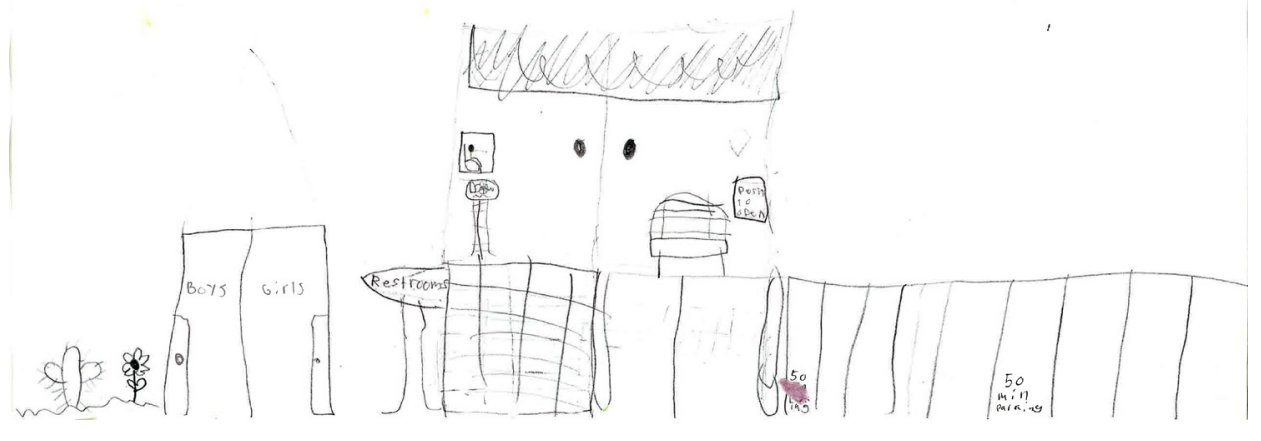

\section{Visitor 11 - Design}

A design by another seasonal coworker who was interested in what the program was about. He did not have time to stay and complete the second stage of design, unfortunately.

His design had the ranger desk central to the VC. Visitors enter from the east with animal exhibits to their right and plant exhibits to their left. A detailed "elevated map" of the park to the right of the desk depicts the dunes from wetlands to alpine tundra. To the right of the map is a water bottle fill station, to the left is an exhibit on the park's history, and directly behind are the restrooms. Like Visitor 1, his design is circular, open, and panoramic, with benches facing windows to the west and observation decks with telescopes outside.

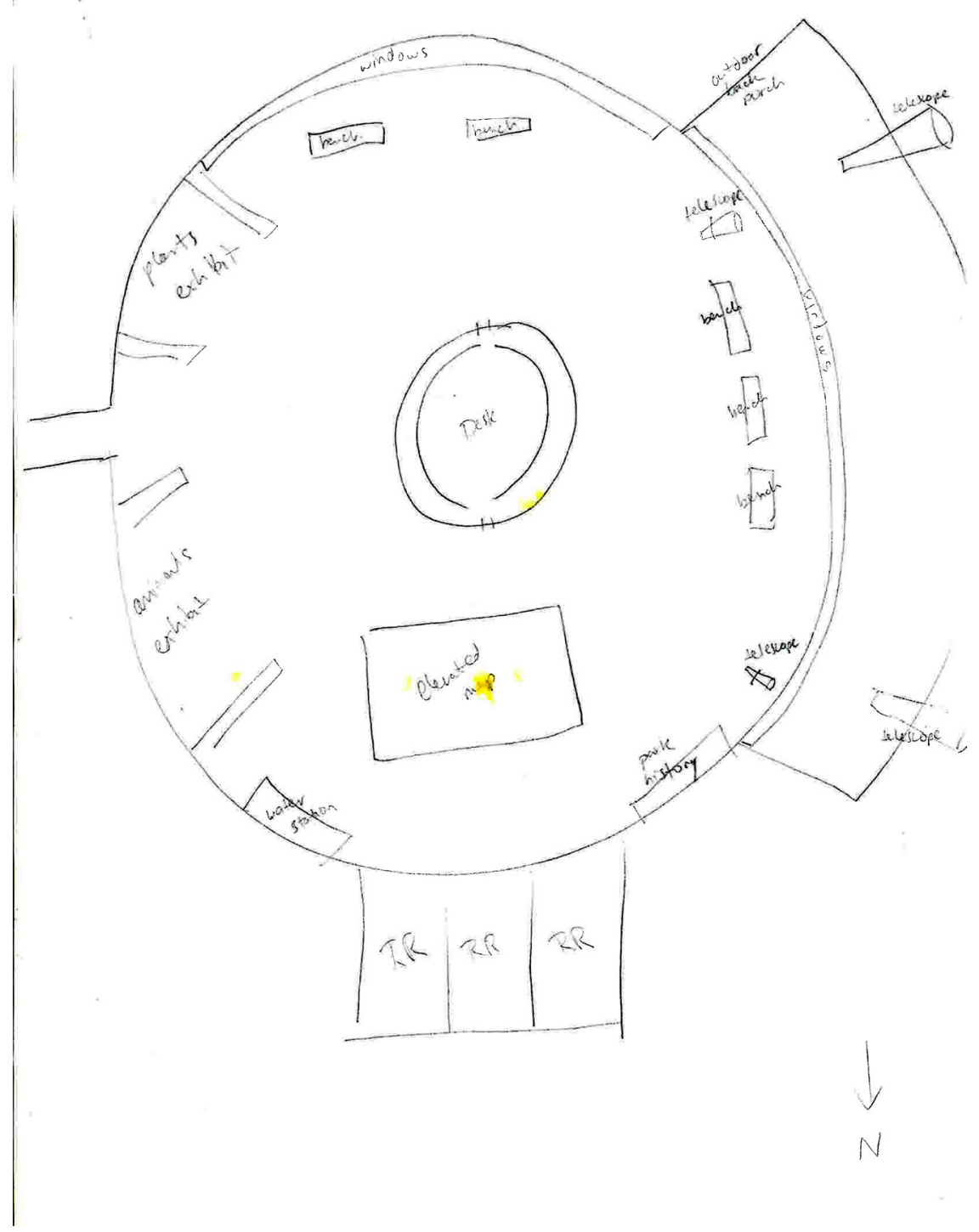


Visitor 12 - Concept

This visitor's design was focused on incorporating a dune field aesthetic to the VC. He wanted an interactive playground with a fountain outside for his kids (who were too young to provide their own input and thoroughly enjoyed playing with the modeling clay while he drew).

\section{Visitor 13 - Design}

A design by an international visitor from Germany, he a professor of entomology and author of several articles as well as a new book on fruit flies.

His design, as one might expect, highlights the insects within the park in order to make them more attractive. First, visitors are greeted by a fountain highlighted in a well-lit lobby. The curved wall on the right holds a multi-screen video detailing the park's story in a comprehensive way, not just "four slides." Visitors then encounter a "Nature Library" containing books and media on the park's natural systems with a café to the right and a lounge to the left surrounding the insect displays. The shop is visible through the glass displays of the park's butterflies, beetles, moths, and endemic species. When he learned that the same company who did the previous

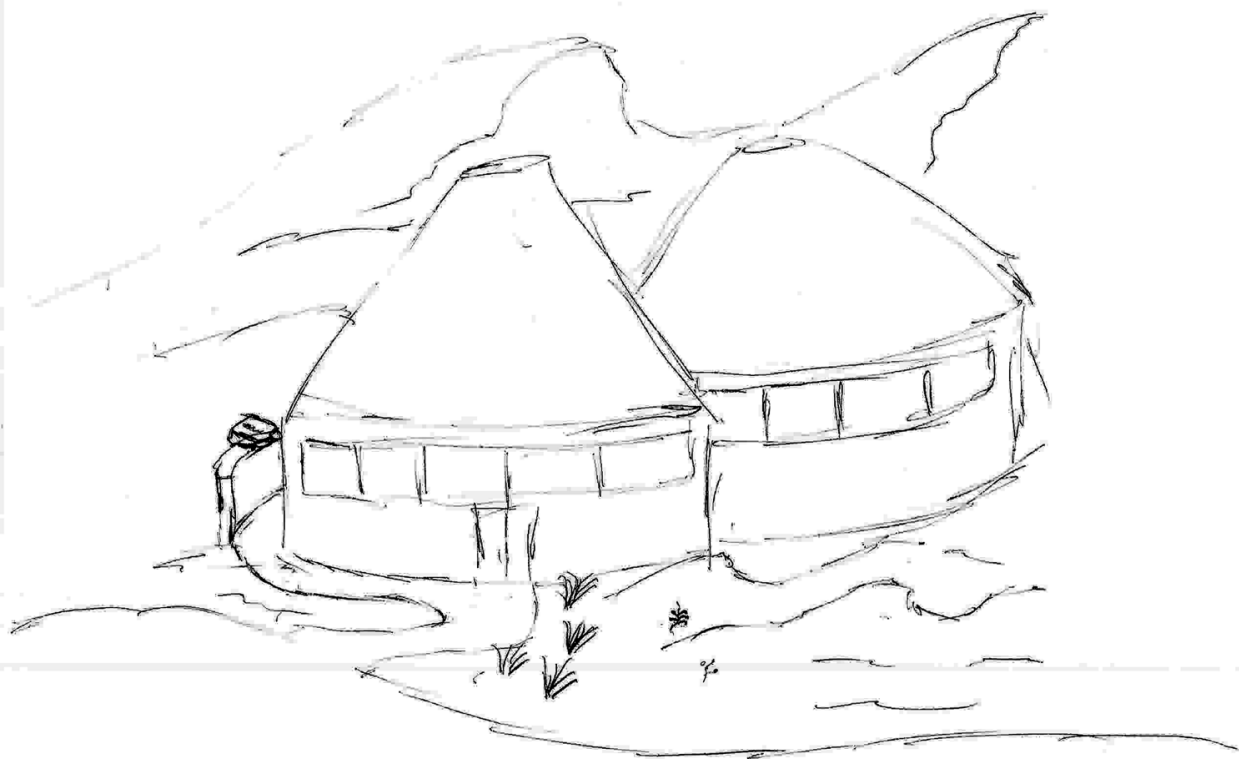

- main roon more displays / Gigger displays, mpdated displays Cinsect dirplays need to be more athractive and accurate, perhaps a lage display of locall butterfies

- entrance hall meeds to have nowe lizh displays (it's a prothy dare room

- larger screen, display more than 4 shides, it footes lice a wrcbsite

- put a sandfrox with a creek owbide the gean windorr.

Put a cafe' with ice cream wasety in the poom where we are mous, open
scaling owbide mear peayground

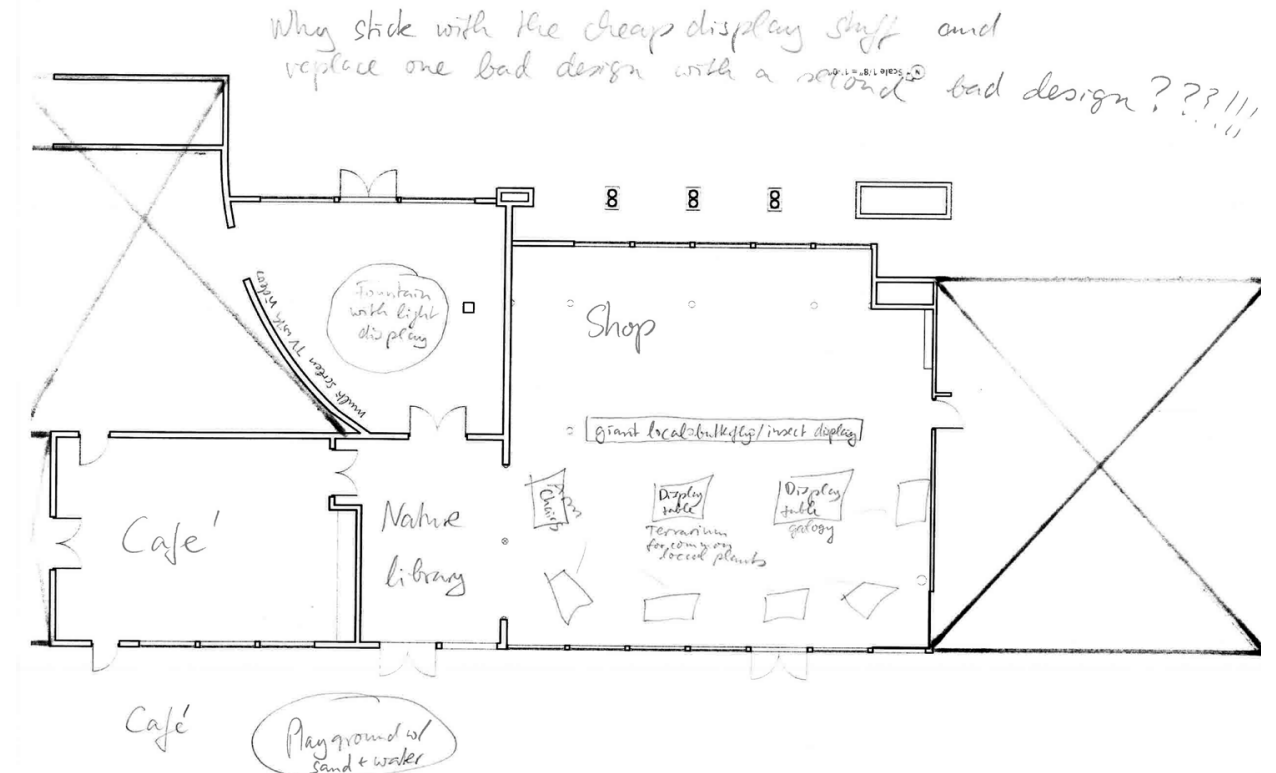

exhibits won the bid to do the upcoming renovation and was shown Design Schematic 4, he wrote "Why stick with the cheap display stuff and replace one bad design with a second bad design???!!!" 


\section{Visitor 14}

Visitors 14 and 15 were traveling together.

This visitor's design initially featured a fountain of sorts outside the VC overlooking the dunes with a surge-flow replicating stream flowing into a small pond that visitors could use to wash sand off their feet (top drawing). The entrance and lobby space is well-lit with clerestory windows and includes screens with real-time information on weather, wildlife sightings, and additional information such as the scheduled ranger programs and upcoming events. She utilizes green technologies to create an eco-friendly VC.

Her implemented design "mirrors" the existing wall in the lobby, adding a second curved wall to the left. The entrance is extended south and west. The space is well-lit with clerestory windows and curved walls encouraging counter-clockwise movement. Visitors walk along the curved wall being met first by real-time info screens. From there, visitors who need immediate assistance may seek a ranger located at the central desk, whereas visitors who are there to enjoy learning may walk along exhibits detailing "natural history" of the park. (She stated "for me Natural History is an all-encompassing term for the different aspects of the park" so in this design, all aspects from geology to cultural history are coherently combined in a time-line along the walls). Once they have completed their walk, they end up at the ranger
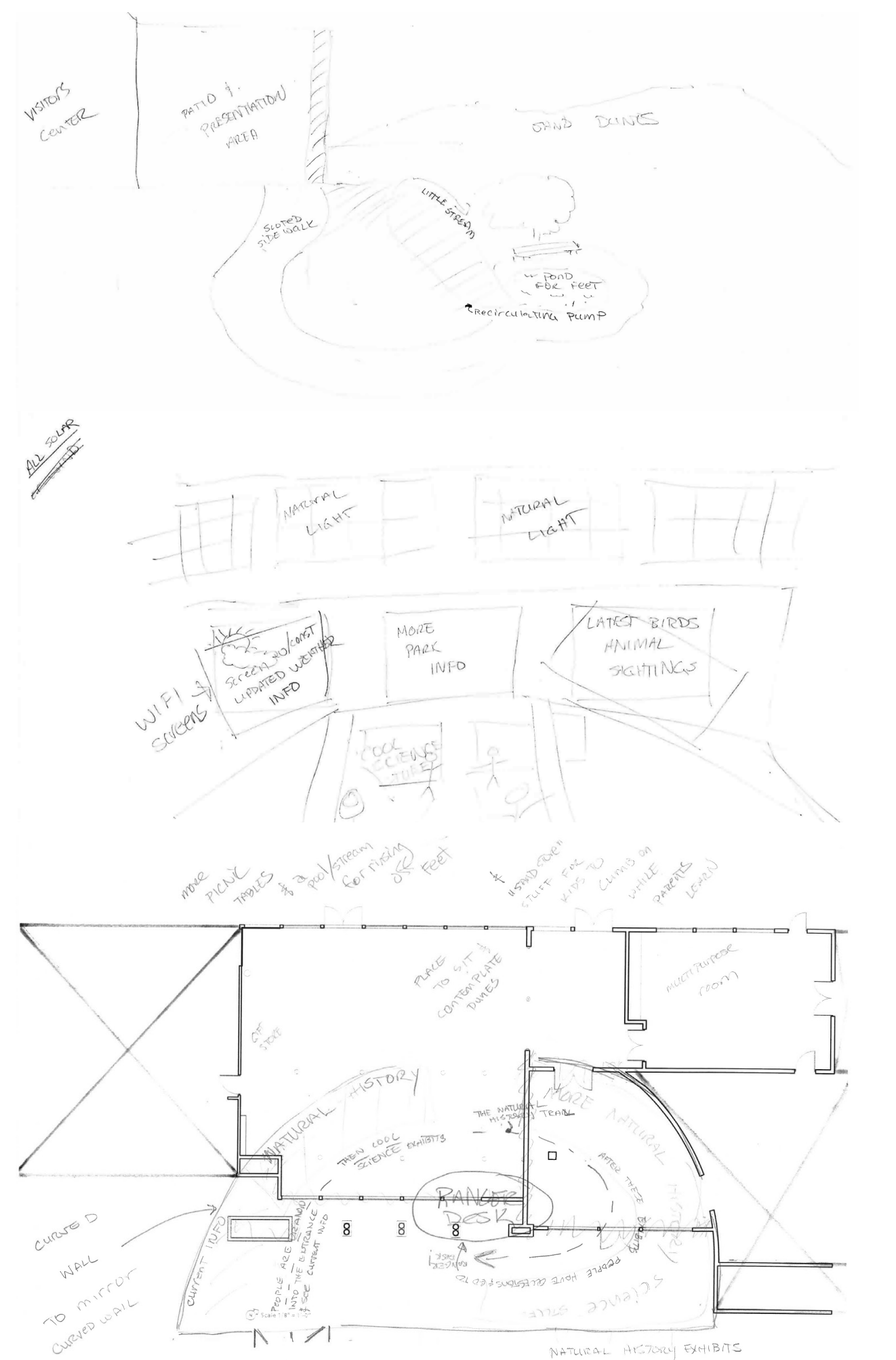

desk so that they can get oriented and have any lingering questions answered. Beyond this space the gift store is to the left, a contemplative lounge with views facing the dunes straight ahead, and the multipurpose movie/program room to the right. Out on the porch is where visitors find the fountain, overlooking the dunes, with a surge-flow replicating stream flowing into a small pond used for washing sand off their feet. Everything is solar powered and utilizes green technologies to uphold an eco-friendly VC. 


\section{Visitor 15}

Her design was all about having an open "covered breezeway with benches and a great view of the dunes" made with "natural materials [like] timber" that complement the park, such as "sandstone." This design is modular with three linked volumes and two "breezeways" for natural cooling and easy access to views of the dunes between them. Each volume holds a different program, one being a gift shop, the next a museum/science center, and the last holding facilities such as restrooms. The science center includes a state of the art interactive display detailing "the connection of the water, sand, + wind" in order for visitors to gain a better understanding of "how the dunes got there."

Her implemented design simplifies the multi-breezeway concept into a single corridor that separates the science center and gift shop from the movie room and restrooms. This gives visitors a direct view of the dune field from the parking area. In the southwest half, the desk is directly in front of the door to ranger and WNPA office spaces. The southeast wall has moved further out to make more room for the science center and gift shop. The north wall of the science center is curved to mirror the restroom access wall with benches along the breezeway. On the north east side of the breezeway, visitors find the movie room and access to the restrooms. The movie room now includes a snack bar catty-corner to the screen.
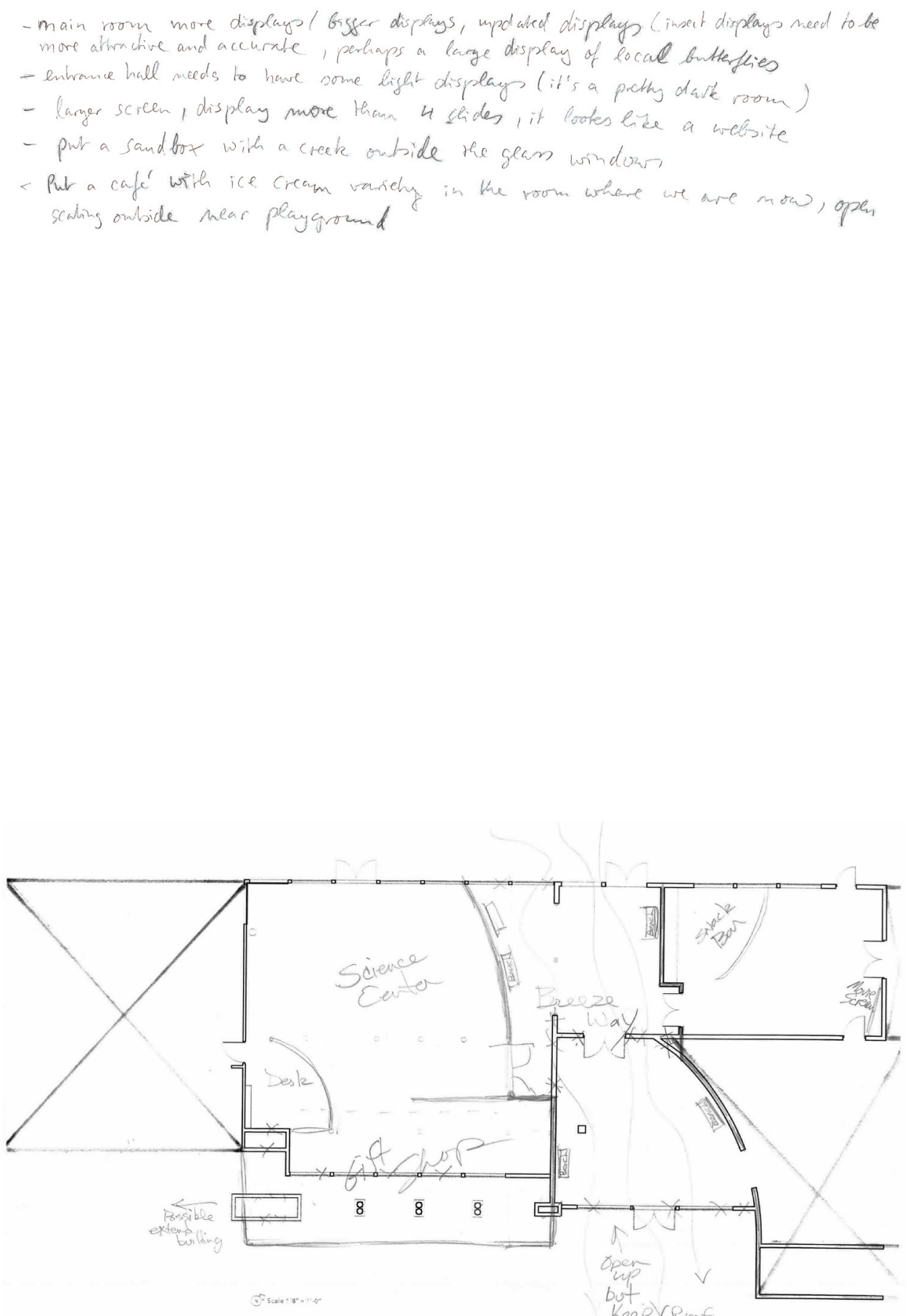
